Check for updates

Cite this: RSC Adv., 2019, 9, 27294

Received 1st July 2019

Accepted 26th August 2019

DOI: 10.1039/c9ra04961d

rsc.li/rsc-advances

\title{
Synthesis and discovery of $18 \beta$-glycyrrhetinic acid derivatives inhibiting cancer stem cell properties in ovarian cancer cells $\uparrow$
}

\author{
Xiaojing Li, (D) *ab Yihua Liu, ${ }^{\mathrm{C}}$ Na Wang, ${ }^{a}$ Yuyu Liu, ${ }^{\mathrm{d}}$ Shuai Wang, ${ }^{a}$ Hongmin Wang, ${ }^{a}$ \\ Aihua Li $\mathrm{i}^{\mathrm{e}}$ and Shaoda Ren ${ }^{\star \mathrm{C}}$
}

\begin{abstract}
Despite advances in ovarian cancer treatment, the five-year overall survival rate is less than $30 \%$ with the presence of cancer stem cells (CSCs). To develop CSC-targeting therapy, a series of $18 \beta$-glycyrrhetinic acid (GA) derivatives containing cinnamamide moiety have been designed, synthesized, and screened for their antiproliferative activity in SKOV3 and OVCAR3 cells. Most of the compounds exhibited stronger antiproliferative activity than GA, and compound $7 \mathrm{c}$ was the most active one. Further biological studies showed that compound 7c could induce apoptosis and suppress migration. In addition, compound 7c could not only observably decrease the colony formation and sphere formation ability, but also significantly reduce the $\mathrm{CD}_{4} 4^{+}, \mathrm{CD}_{133^{+}}$, and $\mathrm{ALDH}^{+}$subpopulation in SKOV3 and OVCAR3 cells. In conclusion, these results indicate that compound $7 \mathrm{c}$ is a promising anti-CSC agent for further antiovarian cancer studies.
\end{abstract}

\section{Introduction}

Ovarian cancer is a highly heterogeneous neoplasm in histology, biological properties, and one of the most deadly malignant tumours of the female reproductive organs. ${ }^{1}$ Over $70 \%$ of ovarian cancer patients would experience recurrence, and the five-year overall survival rate is less than $30 \% .{ }^{2}$ The current standard treatment of advanced ovarian cancer is cytoreductive surgery followed the chemotherapy treatment of a combination of cisplatin or carboplatin with paclitaxel. Standard treatment can eliminate the size of primary tumours and the bulk of cancer cells, but complete tumour eradication is not always achieved due to the presence of cancer stem cells (CSCs). ${ }^{3}$

CSCs account for about $0.1 \%$ of the cancer cells and have been separated from multiple solid tumours, including ovarian cancer, breast, brain, colon, prostate, and so on. ${ }^{4}$ Over the years, identification of CSCs depends on the specific markers on the surfaces of cell membranes and intracellular markers,

aLaboratory of Drug Discovery and Design, School of Pharmacy, Liaocheng University, Liaocheng 252000, China. E-mail: lixiaojing@lcu.edu.cn

${ }^{b}$ Department of Medicinal Chemistry, Key Laboratory of Chemical Biology (Ministry of Education), School of Pharmacy, Shandong University, Jinan 250012, China

${ }^{c}$ Central Laboratory, Liaocheng People's Hospital, Liaocheng 252000, China. E-mail: zslrsd@163.com

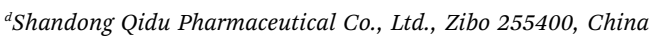

${ }^{e}$ Department of Obstetrics and Gynecology, Liaocheng People's Hospital, Liaocheng 252000, China

$\dagger$ Electronic supplementary information (ESI) available. See DOI: $10.1039 / \mathrm{c} 9 \mathrm{ra} 04961 \mathrm{~d}$ including CD44, CD133, and aldehyde dehydrogenase (ALDH). ${ }^{5}$ CSCs display differentiation and self-renewal, and can form secondary or tertiary tumours. Accumulating evidence has proved that CSCs are linked to cancer initiation, progression, metastasis, relapse, and resistance to conventional therapies. ${ }^{6}$ In ovarian cancer, high expression of the CSC transcription factor was independently associated with poor overall survival. ${ }^{3,7}$ Thus, targeted therapy of CSCs is considered a potential therapeutic strategy against ovarian cancer. ${ }^{8}$

Natural compounds have aroused increasing attention in the field of cancer and CSCs due to their high activity and low side effects. ${ }^{9-11}$ Currently, about $60 \%$ of approved anticancer drugs come from unmodified natural products, their semisynthetic derivatives, or molecules synthesized based on natural products. $^{12,13} 18 \beta$-glycyrrhetinic acid (GA, 1, Fig. 1), a pentacyclic triterpenoid extracted from the root of Licorice, exerts a wide range of pharmacological activities including antiinflammatory, antiviral, anti-oxidative and anticancer properties. ${ }^{14}$ GA has been investigated moderate anti-proliferative activity in ovarian cancer, breast, hepatoma, and stomach cancer cells. ${ }^{15}$ Although GA was not as active as other triterpenes, it can be easily obtained in large amounts. Thus, using GA as a scaffold to develop new low-toxicity and high-effectivity antitumor agents has aroused the great interest of scientists. ${ }^{16-20}$ The other natural compound cinnamic acid isolated from cinnamon or blossom, was found to have extensive physiological, including certain inhibitory activity against cancer cells. ${ }^{21,22}$ The amide bond is an important functional group in medicines as hydrogen bond donors and/or receptors. Therefore, we designed a series of GA derivatives containing 


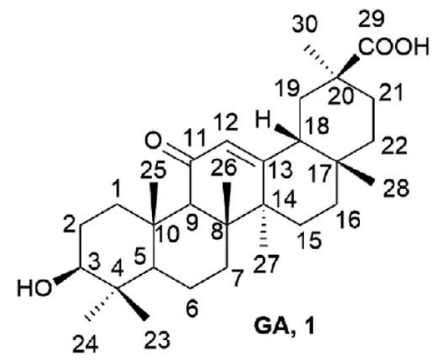

Fig. 1 Structures of 18ß-glycyrrhetinic acid (GA).

cinnamamide moiety to investigate their anti-ovarian cancer activities.

In this study, we designed and synthesized a series of GA derivatives containing CA moiety with piperazine or ethylenediamine (EDA) as linkers. These semisynthetic derivatives were tested for anti-proliferation activities in vitro against ovarian cancer cells. Compound $7 \mathbf{c}$ exhibited the strongest growth inhibition activities and the best selectivity among all of the target compounds. Thus 7c was selected for further biological assays, including apoptosis induction, migration inhibition, and the colony and spheres formation ability, the percentage of ovarian CSCs with $\mathrm{CD} 44^{+}$or $\mathrm{CD} 133^{+}$biomarker, and activity of ALDH.

\section{Results and discussion}

\subsection{Chemistry}

The preparation of the target compounds is outlined in Scheme 1. Compound $\mathbf{2 a - 2 i}$, as the starting material, was reacted with $\mathrm{SOCl}_{2}$ in dichloromethane to obtain the corresponding acyl chloride, and then dropwise added into the solution of anhydrous piperazine in glacial acetic acid to afford $\mathbf{3 a - 3 i}$. Compound $\mathbf{4 a - 4 i}$ was prepared in $63-87 \%$ yield by condensation between GA and 3a-3i in the presence of HATU/DIPEA at

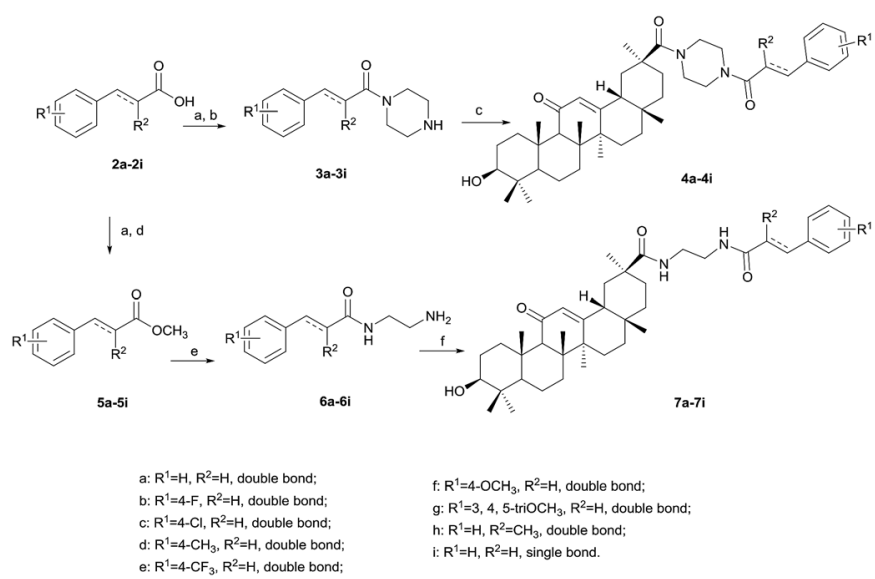

Scheme 1 Reagents and conditions: (a) $\mathrm{SOCl}_{2}$, r.t., $1 \mathrm{~h}$; (b) piperazine, $\mathrm{CH}_{3} \mathrm{COOH}, \mathrm{CH}_{2} \mathrm{Cl}_{2}$, r.t., 2 h; (c) GA, HATU, DIPEA, DMF, $100^{\circ} \mathrm{C}, 5$ h; (d) $\mathrm{CH}_{3} \mathrm{OH}, \mathrm{CH}_{2} \mathrm{Cl}_{2}$, r.t., 0.5 h; (e) EDA, reflux, 2 h; (f) GA, HATU, DIPEA, DMF, r.t., $5 \mathrm{~h}$.
$100{ }^{\circ} \mathrm{C}$ for five hours. Methyl cinnamate 5a-5i can be easily obtained with cinnamoyl chloride and methanol in almost quantitative yield. 6a-6i was achieved by the ammonolysis of the ester group of 5a-5i with EDA under refluxing. Compound $\mathbf{7 a - 7 i}$ was synthesized in a similar way to $\mathbf{4 a - 4 i}$ in $50-70 \%$ yield, except that the reaction temperature changed to room temperature. The structures of GA derivatives were characterized using spectral methods.

\subsection{Biology}

2.2.1 Evaluation of antiproliferative activity and selectivity. Eighteen GA derivatives were screened for their antiproliferative activities in vitro against human ovarian cancer cell line SKOV3 and OVCAR3 by MTT assay. The activities of GA and paclitaxel were used as a reference. As shown in Table 1, the majority of these derivatives exhibited stronger antiproliferative activities against two ovarian cancer cells when compared with GA, but weaker than paclitaxel. Compound 7a-7i with EDA as the linker showed higher antiproliferative activity than $\mathbf{4 a - 4 i}$ with piperazine as the linker. So $7 \mathbf{a}-7 \mathbf{i}$ were selected to test a selectivity index ( $\mathrm{SI}, \mathrm{IC}_{50}$ IOSE80 cell line/ $\mathrm{IC}_{50}$ ovarian cancer cell line), and the results were summarized in Table 2. Compound 7a, 7c, 7e7h exhibited selectivity with SI value superior to 1.0. Among them, compound $7 \mathbf{c}$ demonstrated the most potent antiproliferative activity against the SKOV3 and OVCAR3 cell lines ( $\mathrm{IC}_{50}$ value of $27.9 \mu \mathrm{M}$ and $33.9 \mu \mathrm{M}$ against SKOV3 and OVCAR3 cell lines, respectively). Furthermore, compound 7c was 2-3 times more active in ovarian cell lines than in the normal ovarian epithelial cells, which indicated that the selectivity of $7 \mathrm{c}$ was closed to paclitaxel. These results suggested that the antiproliferative ability was significantly enhanced after the introduction of 4-chloro-substituted aminoethyl cinnamamide moiety at the C-30 carbonyl position of GA. Therefore, we choose the compound $7 \mathbf{c}$ to further investigate the anti-ovarian cancer mechanism of action.

2.2.2 Compound 7c induced apoptosis in SKOV3 and OVCAR3 cells. To investigate whether compound 7c inhibited cells proliferation by regulating apoptosis, cell apoptosis analysis was performed in SKOV3 and OVCAR3 cells. We performed flow cytometry using Annexin V and 7-AAD double staining to quantitatively evaluate apoptosis. The percentages of early and late phase apoptosis were significantly increased by compound 7c in a dose dependent manner (Fig. 2). To investigate the molecular mechanism of apoptosis induced by compound 7c, western blot analysis was conducted with the antibodies for apoptosis-associated proteins. As shown in Fig. 3, the expression of Caspase-3 and Bax was greatly increased, and the level of Bcl-2 was decreased significantly by treatment with 7c in SKOV3 and OVCAR3 cells. These results proved that the apoptosis of cells induced by compound $7 \mathbf{c}$ contributed to their antiproliferative effects.

2.2.3 Compound 7c inhibited the migration of SKOV3 and OVCAR3 cells. The wound healing assay was performed to evaluate the effect of compound $7 \mathbf{c}$ on the migration of SKOV3 and OVCAR3 cells. The cells were treated with compound 7c (22, 44 and $66 \mu \mathrm{M}$ ) for $24 \mathrm{~h}$. As shown in Fig. $4 \mathrm{~A}$ and B, the migration 
Table 1 Cell viability (IC $\mathrm{C}_{50}$ values) of GA derivatives in ovarian cancer cells

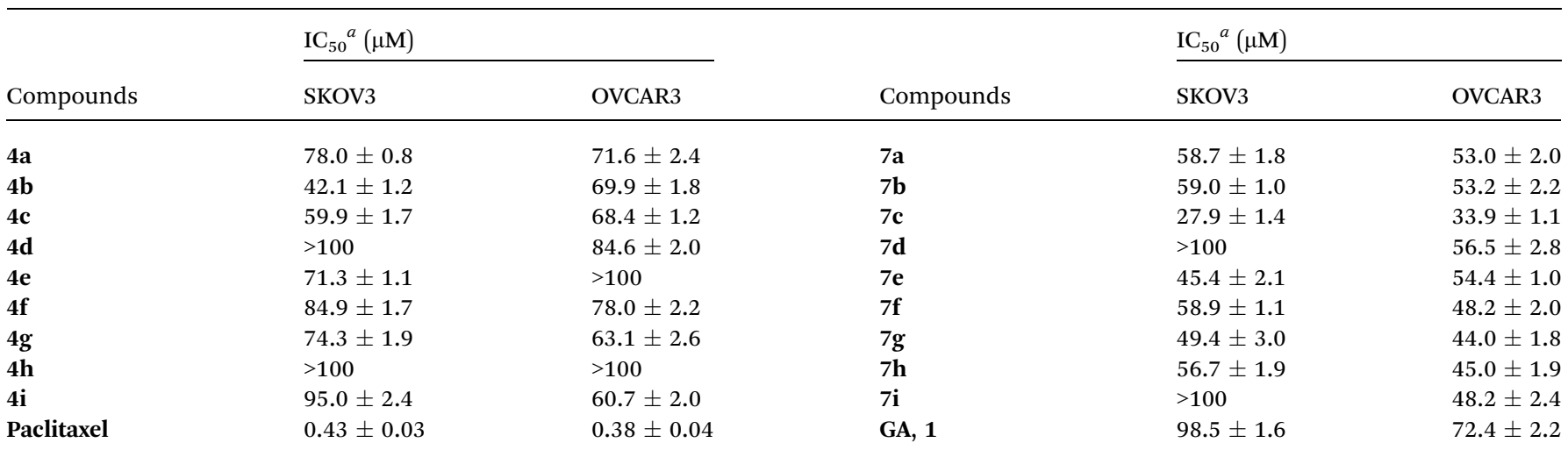

${ }^{a} \mathrm{IC}_{50}$ : concentration that inhibits $50 \%$ of cell growth. The values are presented as the mean $\pm \mathrm{SD}$ (standard error of the mean) from three separated experiments.

rate was significantly suppressed by compound $7 \mathbf{c}$ in SKOV3 and OVCAR3 cells in a dose-dependent manner. The transwell assay demonstrated that the number of transmembrane cells significantly reduced in the concentration of $7 \mathrm{c}$ manner (Fig. 4C and $\mathrm{D}$ ). Taken together, the results indicated that compound $\mathbf{7 c}$ had an inhibitory effect on ovarian cancer cell migration.

2.2.4 Compound 7c inhibited cell colony formation. Colony formation is a basic characteristic of ovarian CSCs and represents the malignant potential. The colony formation assay was performed to study further whether compound $7 \mathbf{c}$ could inhibit forming colonies. As shown in Fig. 5, compound 7c dose-dependently decreased the number of colonies in SKOV3 and OVCAR3 cells. These results demonstrated that compound $7 \mathbf{c}$ significantly suppressed the colony formation and inhibited the unrestricted growth of human ovarian cancer cells.

2.2.5 Compound 7c suppressed the sphere formation. We further determine whether compound $7 \mathbf{c}$ can suppress sphere formation that is one of the characteristics of CSCs. We added compound $7 \mathbf{c}$ to the secondary spheres derived from SKOV 3 and

Table 2 Cell viability ( $\mathrm{IC}_{50}$ values) of GA derivatives 7a-7i against normal ovarian epithelial cells (IOSE80) and selectivity index (SI)

\begin{tabular}{|c|c|c|c|}
\hline \multirow[b]{2}{*}{ Compounds } & \multirow{2}{*}{$\frac{\mathrm{IC}_{50}{ }^{a}(\mu \mathrm{M})}{\text { IOSE80 }}$} & \multicolumn{2}{|l|}{$\mathrm{SI}^{b}$} \\
\hline & & SKOV3 & OVCAR3 \\
\hline $7 a$ & $66.8 \pm 0.9$ & 1.1 & 1.3 \\
\hline $7 \mathbf{b}$ & $48.4 \pm 0.6$ & 0.8 & 0.9 \\
\hline $7 \mathrm{c}$ & $86.7 \pm 0.9$ & 3.1 & 2.6 \\
\hline $7 d$ & $65.7 \pm 3.7$ & - & 1.2 \\
\hline $7 e$ & $71.8 \pm 1.9$ & 1.6 & 1.3 \\
\hline $7 f$ & $92.0 \pm 1.1$ & 1.6 & 1.9 \\
\hline $7 g$ & $53.0 \pm 0.8$ & 1.1 & 1.2 \\
\hline $7 \mathbf{h}$ & $97.6 \pm 5.7$ & 1.7 & 2.2 \\
\hline $7 \mathbf{i}$ & $>100$ & - & - \\
\hline GA & $>100$ & - & - \\
\hline Paclitaxel & $1.7 \pm 0.1$ & 4.0 & 4.5 \\
\hline
\end{tabular}

${ }^{a} \mathrm{IC}_{50}$ : concentration that inhibits $50 \%$ of cell growth. The values are presented as the mean \pm SD (standard error of the mean) from three separated experiments. ${ }^{b}$ SI (selectivity index): IC $_{50}$ IOSE80 cell line/ $\mathrm{IC}_{50}$ ovarian cancer cell line.
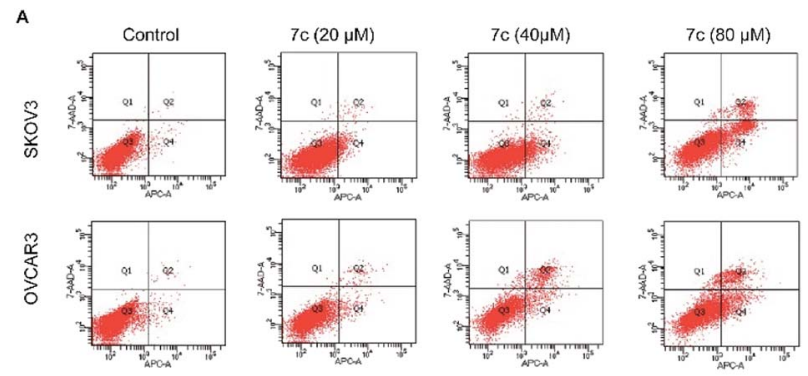

B
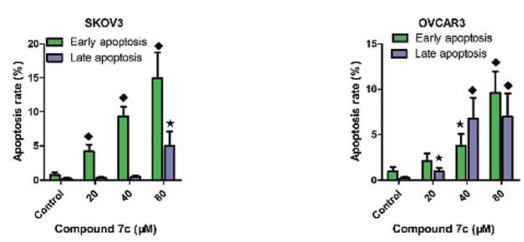

Fig. 2 Compound 7c induced apoptosis in SKOV3 and OVCAR3 cells. Cells were treated with different concentrations of compound $7 c$ for $24 \mathrm{~h}$. (A) Cells were analysed by flow cytometryafter staining with Annexin $V$ and 7AAD. (B) Quantitative analysis of apoptosis was shown. ${ }^{\star} P<0.05, \bullet P<0.01$.

OVCAR3 cells. The sphere formation ability decreased dramatically by showing much fewer number and smaller of spheres treated by compound 7c (Fig. 6). These results suggested that

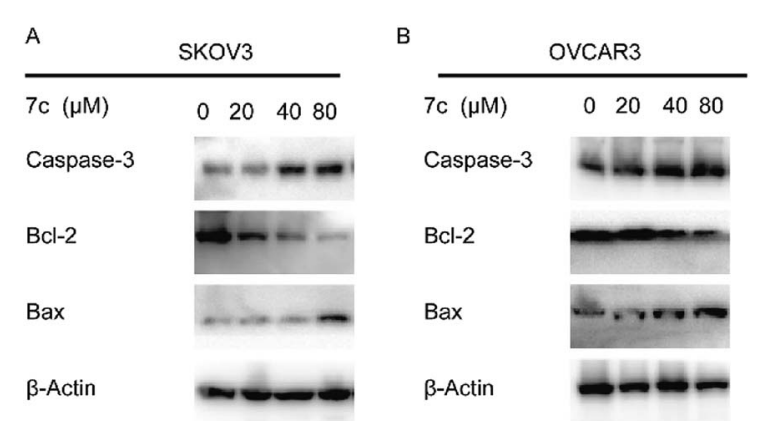

Fig. 3 Effects of compound 7c on the levels of apoptosis-related protein in cells by western blot. (A) The western blot results of 7c in SKOV3 cells. (B) The western blot results of 7c in OVCAR3 cells. 

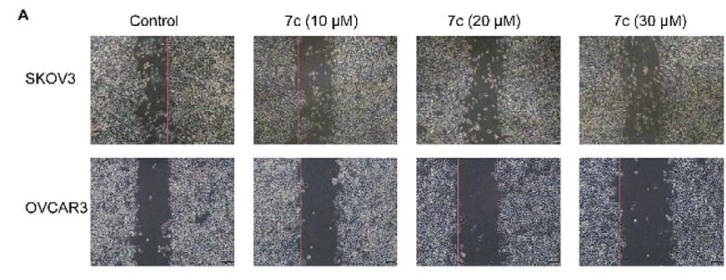

B

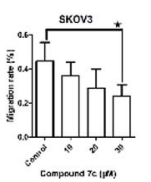

A
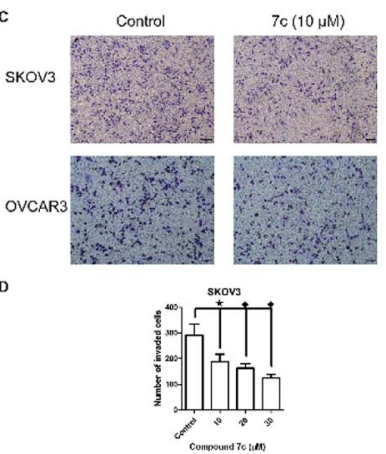
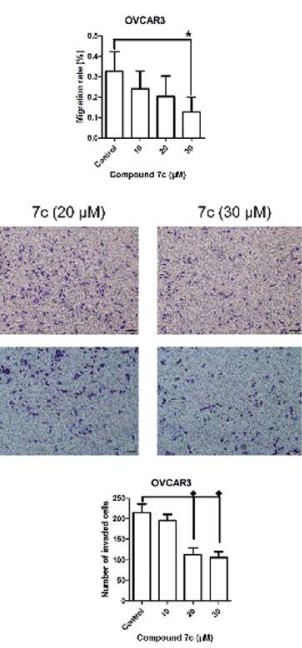

Fig. 4 Compound 7c inhibited the migration of SKOV3 and OVCAR3 cells. (A) Monolayers were wounded by a plastic tip and then incubated for another $24 \mathrm{~h}$ with different concentrations of compound 7c. (B) Quantitative analysis of migration ratewas shown. (C) The transwell assay was performed to study the effect of compound 7c on the migration capacity. (D) Quantitative analysis of migrated cells was shown. Images of the wound morphology were acquired by light microscopy. Scale bar, $100 \mu \mathrm{m} .{ }^{\star} P<0.05,{ }^{\star} P<0.01$.
A SKOV3

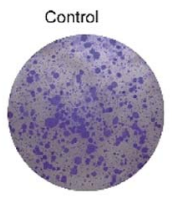

B
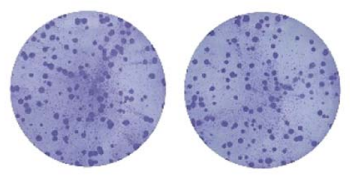

c

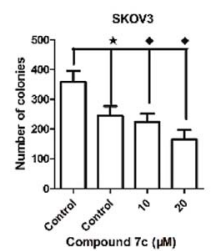

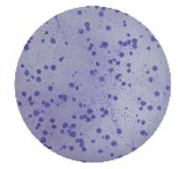
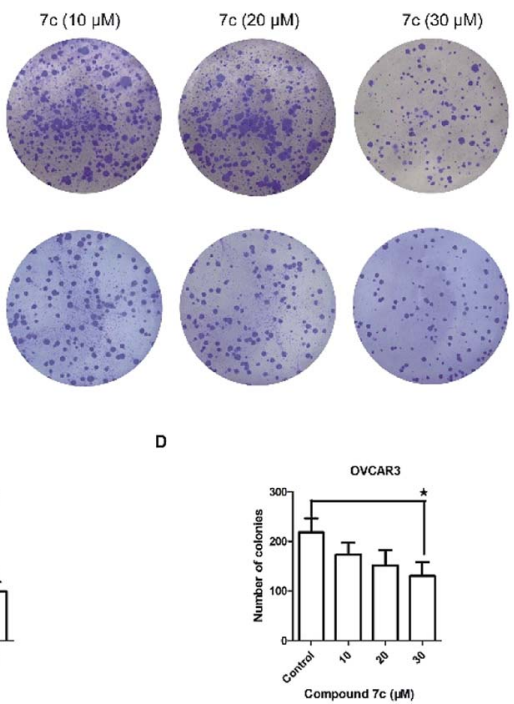

Fig. 5 Compound 7c inhibited the colony formation ability in SKOV3 and OVCAR3 cells. Cells were seeded into 6-well plates and treated by indicated concentrations of compound 7c for 10 days. The colonies were stained with crystal violet dye and photographed. (A) Representative images of the colony formation assay for compound 7c in SKOV3 cells. (B) Representative images of the colony formation assay for compound $7 \mathrm{c}$ in OVCAR3 cells. (C) Quantitative data analysis of colony numbers for compound 7c in SKOV3 cells. (D) Quantitative data analysis of colony numbers for compound 7c in OVCAR3 cells. ${ }^{\star} P<0.05,{ }^{\bullet} P<0.01$.
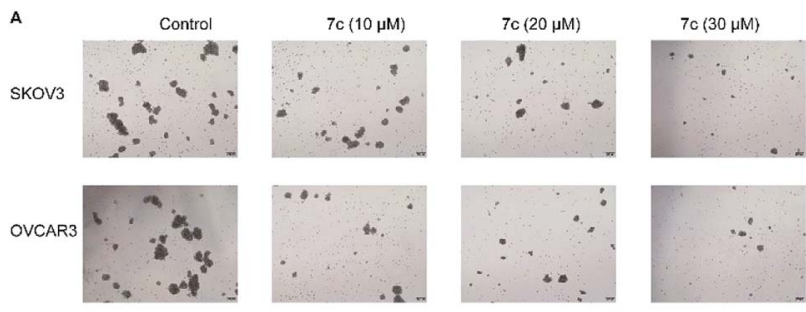

B
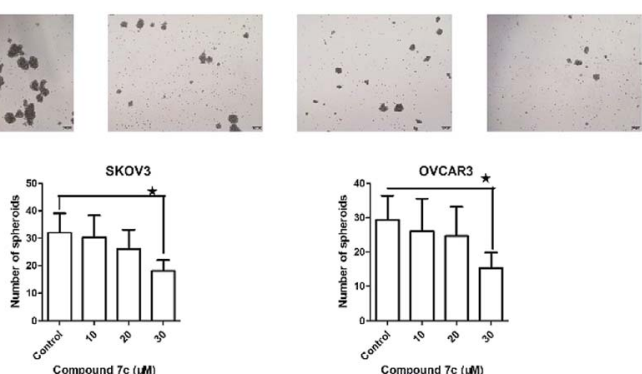

Fig. 6 (A) Compound 7c inhibited the sphere formation ability of SKOV3 and OVCAR3 cells. Single cells were seeded in ultra-low attachment plates. Then cells were seeded to form secondary generation incubated with compound 7c, and the spheroids were photographed. (B) Quantitative analysis of the spheroid numbers was shown. ${ }^{\star} P<0.05$.

compound $7 \mathbf{c}$ attenuated the cancer stem cell characteristics in SKOV3 and OVCAR3 cells.

2.2.6 Compound $7 \mathrm{c}$ reduced the expression of CSC markers in ovarian cancer cells. Convincing evidence from numerous studies reported that CD44 and CD133 was a vital biomarker of the ovarian CSCs. ${ }^{3}$ To further study the effects of compound $7 \mathbf{c}$ on the proportion of the $\mathrm{CD} 44^{+}$and $\mathrm{CD} 133^{+}$in SKOV3 and OVCAR3 cells, the cells were treated with the indicated concentration of compound $7 \mathrm{c}$ for $24 \mathrm{~h}$, followed by staining with the respective antibody (Fig. 7). The results indicated that compound $7 \mathbf{c}$ could markedly reduce the proportion of $\mathrm{CD} 44^{+}$and $\mathrm{CD} 133^{+}$cells, which further confirmed the potent inhibitory effect of compound $7 \mathbf{c}$ in ovarian CSCs.

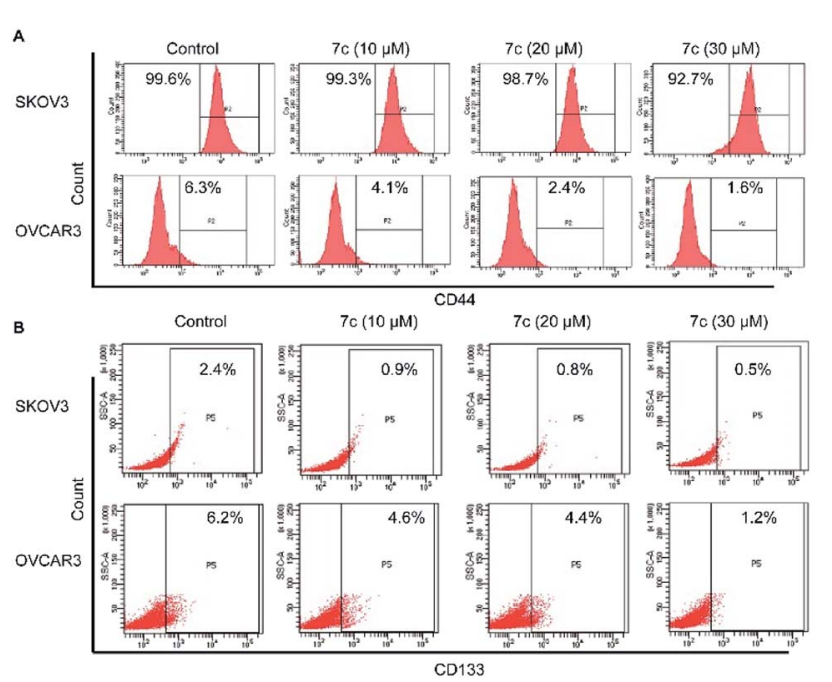

Fig. 7 Compound 7c reduced the $\mathrm{CD} 44^{+}$and $\mathrm{CD} 133^{+}$cell subpopulation of SKOV3 and OVCAR3 cells. (A) The cell population was analysed by flow cytometry with compound 7c for $24 \mathrm{~h}$ in SKOV3. (B) The cell population was analysed by flow cytometry with compound $7 \mathrm{c}$ for $24 \mathrm{~h}$ in OVCAR3 cells. 

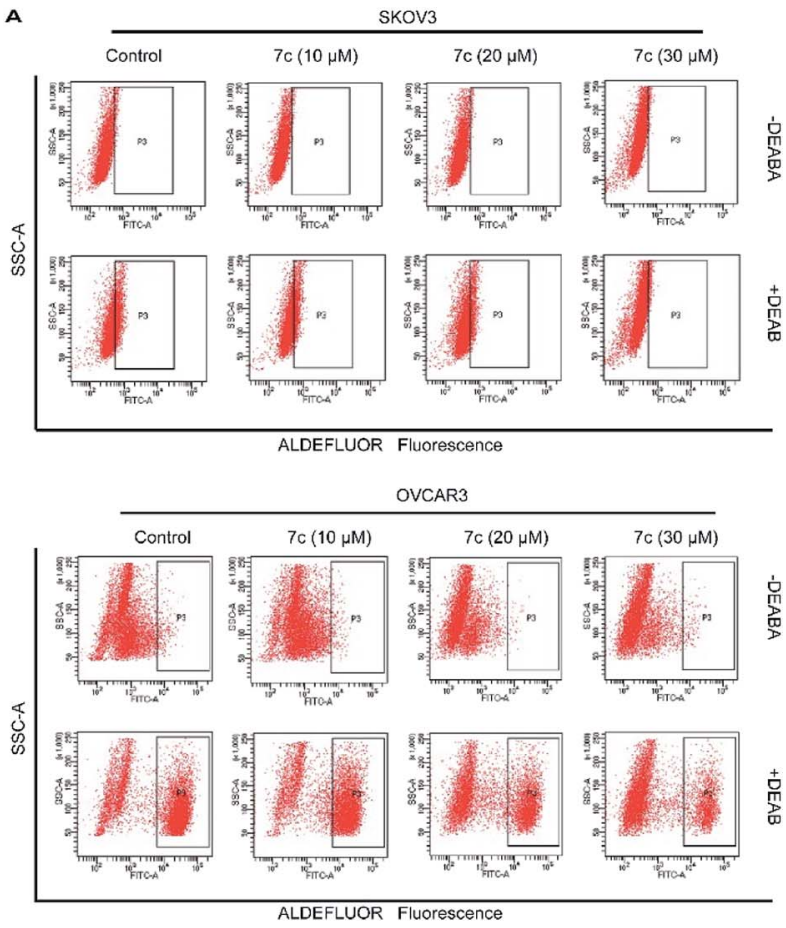

B

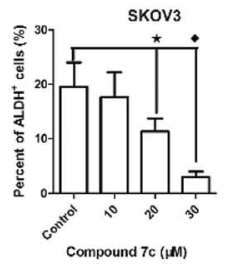

Fig. 8 Compound 7c reduced the population of $\mathrm{ALDH}^{+}$of the subpopulation of SKOV3 and OVCAR3 cells. (A) Cells were treated with compound 7c for $24 \mathrm{~h}$ and FACS analysis of the percentage of $\mathrm{ALDH}^{+}$ cells. (B) Quantification of FACS analysis of the percentage of $\mathrm{ALDH}^{+}$ cells were shown. ${ }^{\star} P<0.05,{ }^{\star} P<0.01$.

2.2.7 Compound 7c reduced the percentage of $\mathrm{ALDH}^{+}$cells in ovarian cancer cells. ALDH enzymatic activity has been reported to be one of the most promising markers of ovarian cancer stem cell, and its activity was studied using the ALDHEFLUOR ${ }^{\mathrm{TM}}$ assay kit. ${ }^{23}$ To further study the effects of compound $7 \mathbf{c}$ on regulating the CSC characteristics, we assessed the percentage of the $\mathrm{ALDH}^{+}$cells in SKOV3 and OVCAR3 cells after treated by compound 7c. The SKOV3 and OVCAR3 cells were exposed to $7 \mathrm{c}$ for $24 \mathrm{~h}$, followed by staining with ALDH reagent and then detection by flow cytometry (Fig. 8). The results indicated that compound 7c treatment dosedependently decreased the percentage of $\mathrm{ALDH}^{+}$cells compared with the control, and provided an additional evidence for the important role of compound $7 \mathbf{c}$ in the elimination of ovarian cancer CSCs.

\section{Conclusions}

In the present study, a series of GA derivatives containing cinnamamide moiety were designed and synthesized. Through evaluation of anticancer activity in ovarian cancer cell lines, the results showed that the antiproliferative activities of GA derivatives were significantly stronger compared with GA. The most potent compound $7 \mathrm{c}$ was selected for further biological studies in SKOV3 and OVCAR3 cells. The compound 7c could induce apoptosis and suppress migration. In addition, the compound 7c could not only observably decreased the colony and sphere formation ability, but also significantly reduced the $\mathrm{CD}_{4}{ }^{+}, \mathrm{CD}_{133}{ }^{+}$, and $\mathrm{ALDH}^{+}$subpopulation in SKOV3 and OVCAR3. In conclusion, these results showed that compound 7c exhibited the potent elimination of ovarian CSCs and need to be further studied.

\section{Experimental section}

\subsection{Chemistry}

Melting points (mp) were determined on an electrically heated $\mathrm{X} 4$ digital visual melting point apparatus. ${ }^{1} \mathrm{H}$ NMR and ${ }^{13} \mathrm{C} \mathrm{NMR}$ spectra were performed on a Bruker ARX-400 or AVANCE NEO500 NMR spectrometer in the indicated solvents (TMS as internal standard) with $\mathrm{CDCl}_{3}$ or $d_{6}$-DMSO as the solvent. Mass spectra (MS) were measured on a Finnigan MAT/USA spectrometer (LC-MS). High-resolution mass spectra (HR-MS) were obtained using a Q-TOF instrument equipped with an ESI source. Most chemicals were commercial suppliers in analytic grade without further purification unless otherwise noted. All of the target compounds were $\geq 95 \%$ purity determined by HPLC analysis.

4.1.1 General procedure for the synthesis of $3 a-3 i$. Compound $2 \mathrm{a}-2 \mathbf{i}(5.0 \mathrm{mmol})$ were added to a round bottom flask containing $\mathrm{SOCl}_{2}(10 \mathrm{~mL})$, and the mixture was stirred at room temperature for $1 \mathrm{~h}$. The solution was removed under reduced pressure to obtain the corresponding acyl chloride. A solution of cinnamic acid chloride in dry dichloromethane (5 $\mathrm{mL}$ ) was dropwise added into the solution of piperazine (10.0 $\mathrm{mmol})$ dissolved in glacial acetic acid $(20 \mathrm{~mL})$ and reacted at room temperature for $2 \mathrm{~h}$. After the reaction was finished, the solution was adjusted to $\mathrm{pH} 7-9$ by $40 \% \mathrm{NaOH}$, and then extracted with dichloromethane $(3 \times)$. The organic layer was dried over anhydrous magnesium sulphate, filtered and evaporated. Purification was performed using column chromatography (dichloromethane/methanol $=50 / 1$ ) to give the desired product 3a-3i.

(E)-3-Phenyl-1-(piperazin-1-yl)prop-2-en-1-one (3a). Yellow solid; mp 86.3-87.5 ${ }^{\circ} \mathrm{C}$; yield $82 \% ;{ }^{1} \mathrm{H}$ NMR (500 MHz, $d_{6}$-DMSO) $\delta$ 7.73-7.68 (2H, m), $7.47(1 \mathrm{H}, \mathrm{d}, J=15.4 \mathrm{~Hz}), 7.43-7.34(3 \mathrm{H}, \mathrm{m})$, $7.23(1 \mathrm{H}, \mathrm{d}, J=15.4 \mathrm{~Hz}), 3.61(2 \mathrm{H}, \mathrm{m}), 3.49(2 \mathrm{H}, \mathrm{m}), 2.69(4 \mathrm{H}, \mathrm{s})$, 1.23 (1H, s); LC-MS: $[\mathrm{M}+\mathrm{H}]^{+} 217.1$.

(E)-3-(4-Fluorophenyl)-1-(piperazin-1-yl)prop-2-en-1-one (3b). Yellow solid; mp 76.7-77.7 ${ }^{\circ} \mathrm{C}$; yield $71 \%$; ${ }^{1} \mathrm{H}$ NMR $\left(500 \mathrm{MHz}, d_{6}-\right.$ DMSO) $\delta 7.77(2 \mathrm{H}, \mathrm{dd}, J=8.6,5.7 \mathrm{~Hz}), 7.45(1 \mathrm{H}, \mathrm{d}, J=15.4 \mathrm{~Hz})$, 7.20 (3H, dd, $J=20.1,12.0 \mathrm{~Hz}), 3.59(2 \mathrm{H}, \mathrm{m}), 3.48(2 \mathrm{H}, \mathrm{m}), 2.67$ $(4 \mathrm{H}, \mathrm{m}), 1.22$ (1H, s); LC-MS: [M + H $]^{+} 234.1$.

(E)-3-(4-Chlorophenyl)-1-(piperazin-1-yl)prop-2-en-1-one (3c). Yellow solid; mp 85.4-86.1 ${ }^{\circ} \mathrm{C}$; yield $73 \%$; ${ }^{1} \mathrm{H}$ NMR $\left(500 \mathrm{MHz}, d_{6}\right.$ DMSO) $\delta 7.82-7.74(2 \mathrm{H}, \mathrm{m}), 7.47$ (1H, d, $J=15.4 \mathrm{~Hz}), 7.25-7.19$ (3H, m), $3.63(2 \mathrm{H}, \mathrm{m}), 3.51(2 \mathrm{H}, \mathrm{m}), 2.72(4 \mathrm{H}, \mathrm{m}), 1.23(1 \mathrm{H}, \mathrm{s})$; LC-MS: $[\mathrm{M}+\mathrm{H}]^{+}$251.2. 
(E)-1-(Piperazin-1-yl)-3-(p-tolyl)prop-2-en-1-one (3d). Yellow solid; mp 77.8-78.4 ${ }^{\circ} \mathrm{C}$; yield 75\%; ${ }^{1} \mathrm{H}$ NMR (500 $\mathrm{MHz}, \mathrm{CDCl}_{3}$ ) $\delta 7.65(1 \mathrm{H}, \mathrm{d}, J=15.4 \mathrm{~Hz}), 7.41(2 \mathrm{H}, \mathrm{d}, J=8.0 \mathrm{~Hz}), 7.17(2 \mathrm{H}, \mathrm{d}, J$ $=7.9 \mathrm{~Hz}), 6.82(1 \mathrm{H}, \mathrm{d}, J=15.4 \mathrm{~Hz}), 3.72-3.66(4 \mathrm{H}, \mathrm{m}), 3.05-2.85$ $(4 \mathrm{H}, \mathrm{m}), 2.36$ (3H, s), $1.25(1 \mathrm{H}, \mathrm{s})$; LC-MS: [M + H $]^{+} 231.1$.

(E)-1-(Piperazin-1-yl)-3-(4-(trifluoromethyl)phenyl)prop-2-en-1one (3e). Yellow solid; mp 83.1-83.3 ${ }^{\circ} \mathrm{C}$; yield 76\%; ${ }^{1} \mathrm{H}$ NMR $(500$ $\mathrm{MHz}, d_{6}$-DMSO) $\delta 7.74(2 \mathrm{H}, \mathrm{d}, J=8.5 \mathrm{~Hz}), 7.44(3 \mathrm{H}, \mathrm{dd}, J=11.9$, $3.3 \mathrm{~Hz}), 7.26(1 \mathrm{H}, \mathrm{d}, J=15.5 \mathrm{~Hz}), 3.60(2 \mathrm{H}, \mathrm{m}), 3.49(2 \mathrm{H}, \mathrm{m}), 2.68$ $(4 \mathrm{H}, \mathrm{m}), 1.22(1 \mathrm{H}, \mathrm{s})$; LC-MS: $[\mathrm{M}+\mathrm{H}]^{+} 285.2$.

(E)-3-(4-Methoxyphenyl)-1-(piperazin-1-yl)prop-2-en-1-one (3f). Yellow solid; mp 79.2-80.4 ${ }^{\circ} \mathrm{C}$; yield 83\%; ${ }^{1} \mathrm{H}$ NMR $\left(500 \mathrm{MHz}, d_{6}\right.$ DMSO) $\delta 7.64(2 \mathrm{H}, \mathrm{d}, J=8.7 \mathrm{~Hz}), 7.42(1 \mathrm{H}, \mathrm{d}, J=15.4 \mathrm{~Hz}), 7.07$ $(1 \mathrm{H}, \mathrm{d}, J=15.3 \mathrm{~Hz}), 6.94(2 \mathrm{H}, \mathrm{d}, J=8.7 \mathrm{~Hz}), 3.78(3 \mathrm{H}, \mathrm{s}), 3.59$ $(2 \mathrm{H}, \mathrm{m}), 3.47$ (2H, m), $2.68(4 \mathrm{H}, \mathrm{m})$; LC-MS: [M + H $]^{+} 247.1$.

(E)-1-(Piperazin-1-yl)-3-(3,4,5-trimethoxyphenyl)prop-2-en-1-one (3g). Yellow solid; mp 81.2-82.5 ${ }^{\circ} \mathrm{C}$; yield $62 \% ;{ }^{1} \mathrm{H}$ NMR $(500$ MHz, $d_{6}$-DMSO) $\delta 7.42(1 \mathrm{H}, \mathrm{d}, J=15.3 \mathrm{~Hz}), 7.16(1 \mathrm{H}, \mathrm{d}, J=15.3$ $\mathrm{Hz}), 7.02(2 \mathrm{H}, \mathrm{s}), 3.81(6 \mathrm{H}, \mathrm{s}), 3.67(3 \mathrm{H}, \mathrm{s}), 3.58(4 \mathrm{H}, \mathrm{m}), 2.74(4 \mathrm{H}$, m), $1.22(1 \mathrm{H}, \mathrm{s})$; LC-MS: $[\mathrm{M}+\mathrm{H}]^{+} 307.3$.

(E)-2-Methyl-3-phenyl-1-(piperazin-1-yl)prop-2-en-1-one

(3h). Yellow solid; mp 85.2-86.1 ${ }^{\circ} \mathrm{C}$; yield $60 \%$; ${ }^{1} \mathrm{H} \mathrm{NMR}\left(500 \mathrm{MHz}, d_{6}{ }^{-}\right.$ DMSO) $\delta 7.38-7.27(5 \mathrm{H}, \mathrm{m}), 6.44(1 \mathrm{H}, \mathrm{s}), 3.43-3.32(4 \mathrm{H}, \mathrm{m})$, 2.69-2.67 (4H, m), 1.98 (3H, d, $J=1.4 \mathrm{~Hz}), 1.22$ (1H, s); LC-MS: $[\mathrm{M}+\mathrm{H}]^{+}$231.2.

3-Phenyl-1-(piperazin-1-yl)propan-1-one (3i). Yellow oil; yield $72 \% ;{ }^{1} \mathrm{H}$ NMR $\left(500 \mathrm{MHz}, d_{6}\right.$-DMSO) $\delta$ 7.30-7.13 (5H, m), 3.36$3.24(4 \mathrm{H}, \mathrm{m}), 2.79-2.77$ (2H, m), 2.59-2.49 (6H, m), $1.22(1 \mathrm{H}, \mathrm{s})$; LC-MS: $[\mathrm{M}+\mathrm{H}]^{+} 219.1$.

4.1.2 General procedure for the synthesis of $4 a-4 i$. GA (100 mg, $0.21 \mathrm{mmol}$ ) was dissolved in DMF $(10 \mathrm{~mL})$, HATU (100 mg, $0.26 \mathrm{mmol}$ ) and DIPEA $(0.16 \mathrm{~mL}, 0.88 \mathrm{mmol}$ ) were added and the mixture was stirred at room temperature for $0.5 \mathrm{~h}$. Then compound $\mathbf{3 a}-\mathbf{3 i}$ were added into the solution and reacted at $100{ }^{\circ} \mathrm{C}$ for $5 \mathrm{~h}$. Upon completion, the mixture was poured into water and filtered under reduced pressure to obtain the crude product. Purification was performed using preparative TLC (dichloromethane/methanol $=30 / 1$ ) to give the desired product $\mathbf{4 a}-\mathbf{4 i}$

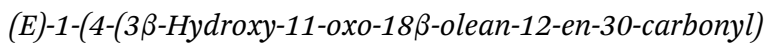
piperazin-1-yl)-3-phenyl-2-propen-1-one (4a). White solid; $\mathrm{mp}$ 169.7-172.2 ${ }^{\circ} \mathrm{C}$; yield 71\%; ${ }^{1} \mathrm{H}$ NMR (400 $\left.\mathrm{MHz}, \mathrm{CDCl}_{3}\right) \delta 7.70$ $(1 \mathrm{H}, \mathrm{d}, J=15.3 \mathrm{~Hz}), 7.52(2 \mathrm{H}, \mathrm{s}), 7.37(3 \mathrm{H}, \mathrm{s}), 6.86(1 \mathrm{H}, \mathrm{d}, J=$ $15.1 \mathrm{~Hz}), 5.69(1 \mathrm{H}, \mathrm{s}), 3.69(8 \mathrm{H}, \mathrm{m}), 3.27-3.15(1 \mathrm{H}, \mathrm{m}), 2.77(1 \mathrm{H}$, $\mathrm{d}, J=12.8 \mathrm{~Hz}), 2.33(2 \mathrm{H}, \mathrm{m}), 2.12-1.92(3 \mathrm{H}, \mathrm{m}), 1.88-1.19(1 \mathrm{H}$, $\mathrm{m}), 1.68-1.58(5 \mathrm{H}, \mathrm{m}), 1.50-1.39(5 \mathrm{H}, \mathrm{m}), 1.36(3 \mathrm{H}, \mathrm{s}), 1.24(3 \mathrm{H}$, s), 1.22-1.14 (2H, m), $1.12(3 \mathrm{H}, \mathrm{s}), 1.11(3 \mathrm{H}, \mathrm{s}), 1.04(1 \mathrm{H}, \mathrm{d}, J=$ $1.3 \mathrm{~Hz}), 1.00$ (3H, s), 0.96-0.91 (1H, m), $0.81(3 \mathrm{H}, \mathrm{s}), 0.80(3 \mathrm{H}, \mathrm{s})$, $0.69(1 \mathrm{H}, \mathrm{d}, J=11.2 \mathrm{~Hz}) ;{ }^{13} \mathrm{C} \mathrm{NMR}\left(101 \mathrm{MHz}, \mathrm{CDCl}_{3}\right) \delta 200.06$, $174.25,169.27,143.53,134.96,129.82,128.81$ (3C), 128.60, 127.82 (2C), 116.45, 78.72, 61.77, 54.90, 48.03, 45.25, 43.94 (2C), 43.88 (2C), 43.25, 39.09 (2C), 37.70, 37.05, 33.01, 32.78, 31.76, 29.67, 28.39, 28.06, 27.26, 27.05, 26.67, 26.37, 23.16 (2C), 18.65, 17.45, 16.36, 15.56; HRMS (ESI): $m / z$ calcd for $\mathrm{C}_{43} \mathrm{H}_{61} \mathrm{~N}_{2} \mathrm{O}_{4}[\mathrm{M}+$ $\mathrm{H}]^{+}$669.4631, found 669.4654.

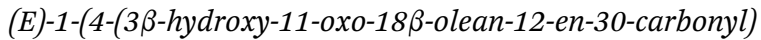
piperazin-1-yl)-3-(4-(trifluoromethyl)phenyl)-2-propen-1-one (4b). White solid; mp 179.9-182.1 ${ }^{\circ} \mathrm{C}$; yield 67\%; ${ }^{1} \mathrm{H}$ NMR $(400 \mathrm{MHz}$, $\left.\mathrm{CDCl}_{3}\right) \delta 7.65(1 \mathrm{H}, \mathrm{d}, J=15.3 \mathrm{~Hz}), 7.51(2 \mathrm{H}, \mathrm{dd}, J=8.4,5.5 \mathrm{~Hz})$, $7.06(2 \mathrm{H}, \mathrm{t}, J=8.5 \mathrm{~Hz}), 6.77(1 \mathrm{H}, \mathrm{d}, J=15.4 \mathrm{~Hz}), 5.67(1 \mathrm{H}, \mathrm{s})$, $3.68(8 \mathrm{H}, \mathrm{m}), 3.23-3.19(1 \mathrm{H}, \mathrm{m}), 2.77(1 \mathrm{H}, \mathrm{d}, J=13.5 \mathrm{~Hz}), 2.33-$ $2.28(2 \mathrm{H}, \mathrm{m}), 2.07-1.96(3 \mathrm{H}, \mathrm{m}), 1.87-1.80(1 \mathrm{H}, \mathrm{m}), 1.68-1.57$ (5H, m), 1.49-1.39 (5H, m), $1.36(3 \mathrm{H}, \mathrm{s}), 1.24(3 \mathrm{H}, \mathrm{s}), 1.18(2 \mathrm{H}, \mathrm{d}$, $J=15.2 \mathrm{~Hz}$ ), $1.12(3 \mathrm{H}, \mathrm{s}), 1.11(3 \mathrm{H}, \mathrm{s}), 1.04(1 \mathrm{H}, \mathrm{s}), 0.99(3 \mathrm{H}, \mathrm{s})$, 0.96-0.94 (1H, m), $0.81(3 \mathrm{H}, \mathrm{s}), 0.79(3 \mathrm{H}, \mathrm{s}), 0.69(1 \mathrm{H}, \mathrm{d}, J=11.3$ $\mathrm{Hz}) ;{ }^{13} \mathrm{C}$ NMR (101 MHz, $\left.\mathrm{CDCl}_{3}\right) \delta 200.05,174.26,169.27$, $165.50,163.56(\mathrm{~d}, J=251.5 \mathrm{~Hz}), 142.28,131.20(\mathrm{~d}, J=4.0 \mathrm{~Hz})$, $129.63(2 \mathrm{C}, J=8.1 \mathrm{~Hz}), 128.59,116.14(\mathrm{~d}, J=2.0 \mathrm{~Hz}), 115.92(2 \mathrm{C}$, $\mathrm{d}, J=21.2 \mathrm{~Hz}), 78.71,61.77,54.91,48.07,45.25,43.94$ (2C), 43.84 (2C), 43.26, 39.10 (2C), 37.69, 37.06, 33.06, 32.78, 31.77 (2C), 28.39, 28.07, 27.27, 27.03, 26.68, 26.37, 23.14 (2C), 18.65, 17.46, 16.36, 15.56; HRMS (ESI): $m / z$ calcd for $\mathrm{C}_{43} \mathrm{H}_{60} \mathrm{FN}_{2} \mathrm{O}_{4}[\mathrm{M}+$ $\mathrm{H}]^{+} 687.4537$, found 687.4558 .

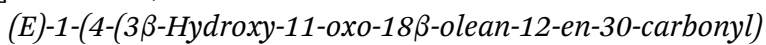
piperazin-1-yl)-3-(4-(chloro)phenyl)-2-propen-1-one (4c). White solid; mp 168.5-169.6 ${ }^{\circ} \mathrm{C}$; yield 73\%; ${ }^{1} \mathrm{H}$ NMR (400 MHz, $\mathrm{CDCl}_{3}$ ) $\delta 7.64(1 \mathrm{H}, \mathrm{d}, J=15.5 \mathrm{~Hz}), 7.46(2 \mathrm{H}, \mathrm{d}, J=7.8 \mathrm{~Hz}), 7.35(2 \mathrm{H}, \mathrm{d}, J$ $=8.2 \mathrm{~Hz}), 6.83(1 \mathrm{H}, \mathrm{d}, J=14.9 \mathrm{~Hz}), 5.68(1 \mathrm{H}, \mathrm{s}), 3.68(8 \mathrm{H}, \mathrm{m})$, $3.24-3.20$ (1H, m), 2.78 (1H, d, $J=12.9 \mathrm{~Hz}), 2.30(2 \mathrm{H}, \mathrm{d}, J=21.1$ $\mathrm{Hz}), 2.09-1.97(3 \mathrm{H}, \mathrm{m}), 1.87-1.80(1 \mathrm{H}, \mathrm{m}), 1.69-1.58(5 \mathrm{H}, \mathrm{m})$, 1.49-1.40 (5H, m), 1.36 (3H, s), 1.24 (3H, s), $1.19(2 \mathrm{H}, \mathrm{d}, J=12.3$ $\mathrm{Hz}), 1.12(3 \mathrm{H}, \mathrm{s}), 1.11(3 \mathrm{H}, \mathrm{s}), 1.05(1 \mathrm{H}, \mathrm{s}), 1.00(3 \mathrm{H}, \mathrm{s}), 0.95(1 \mathrm{H}$, $\mathrm{d}, J=9.5 \mathrm{~Hz}), 0.81(3 \mathrm{H}, \mathrm{s}), 0.80(3 \mathrm{H}, \mathrm{s}), 0.69(1 \mathrm{H}, \mathrm{d}, J=12.1 \mathrm{~Hz})$; ${ }^{13} \mathrm{C}$ NMR $\left(101 \mathrm{MHz}, \mathrm{CDCl}_{3}\right) \delta 200.07,174.27,169.29,165.38$, 142.14, 135.64, 133.45, 129.06 (2C), 128.99 (2C), 128.58, 116.96, 78.71, 61.77, 54.91, 48.07, 45.25, 43.94 (2C), 43.83 (2C), 43.26, $39.11,39.10,37.69,37.06,33.05,32.78,31.77$ (2C), 28.38, 28.07, 27.26, 27.03, 26.68, 26.37, 23.14 (2C), 18.65, 17.45, 16.35, 15.56; HRMS (ESI): $m / z$ calcd for $\mathrm{C}_{43} \mathrm{H}_{60} \mathrm{ClN}_{2} \mathrm{O}_{4}[\mathrm{M}+\mathrm{H}]^{+}$703.4242, found 703.4258 .

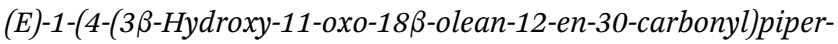
azin-1-yl)-3-(p-tolyl)-2-propen-1-one (4d). White solid; mp 172.8$173.9{ }^{\circ} \mathrm{C}$; yield $87 \% ;{ }^{1} \mathrm{H}$ NMR $\left(400 \mathrm{MHz}, \mathrm{CDCl}_{3}\right) \delta 7.67(1 \mathrm{H}, \mathrm{d}, J=$ $15.3 \mathrm{~Hz}), 7.42(2 \mathrm{H}, \mathrm{d}, J=7.8 \mathrm{~Hz}), 7.18(2 \mathrm{H}, \mathrm{d}, J=7.7 \mathrm{~Hz}), 6.80$ $(1 \mathrm{H}, \mathrm{d}, J=15.2 \mathrm{~Hz}), 5.68(1 \mathrm{H}, \mathrm{s}), 3.67(8 \mathrm{H}, \mathrm{m}), 3.23-3.19(1 \mathrm{H}, \mathrm{m})$, $2.77(1 \mathrm{H}, \mathrm{d}, J=13.1 \mathrm{~Hz}), 2.36(3 \mathrm{H}, \mathrm{s}), 2.31(2 \mathrm{H}, \mathrm{d}, J=13.0 \mathrm{~Hz})$, 2.11-1.94 (3H, m), 1.85-1.79 (1H, m), 1.66-1.57 (5H, m), 1.47$1.38(5 \mathrm{H}, \mathrm{m}), 1.35(3 \mathrm{H}, \mathrm{s}), 1.23(3 \mathrm{H}, \mathrm{s}), 1.18(2 \mathrm{H}, \mathrm{d}, J=13.5 \mathrm{~Hz})$, $1.12(3 \mathrm{H}, \mathrm{s}), 1.10(3 \mathrm{H}, \mathrm{s}), 1.04(1 \mathrm{H}, \mathrm{s}), 0.99(3 \mathrm{H}, \mathrm{s}), 0.96-0.94(1 \mathrm{H}$, $\mathrm{m}), 0.81(3 \mathrm{H}, \mathrm{s}), 0.79(3 \mathrm{H}, \mathrm{s}), 0.69(1 \mathrm{H}, \mathrm{d}, J=11.6 \mathrm{~Hz}) ;{ }^{13} \mathrm{C} \mathrm{NMR}$ $\left(101 \mathrm{MHz}, \mathrm{CDCl}_{3}\right) \delta 200.06,174.27,169.29,165.89,143.55$, 140.16, 132.23, 129.54 (2C), 128.61, 127.82 (2C), 115.28, 78.71, 61.78, 54.93, 48.04, 45.27, 43.95 (2C), 43.92 (2C), 43.27, 39.11 (2C), 37.72, 37.07, 32.99, 32.80, 31.87, 31.78, 28.40, 28.09, 27.28, 27.04, 26.70, 26.38, 23.16 (2C), 21.43, 18.67, 17.47, 16.37, 15.59; HRMS (ESI): $m / z$ calcd for $\mathrm{C}_{44} \mathrm{H}_{63} \mathrm{~N}_{2} \mathrm{O}_{4}[\mathrm{M}+\mathrm{H}]^{+} 683.4788$, found 683.4810 .

(E)-1-(4-(3 $\beta$-Hydroxy-11-oxo-18 $\beta$-olean-12-en-30-carbonyl) piperazin-1-yl)-3-(4-(trifluoromethyl)phenyl)-2-propen-1-one (4e). White solid; mp 172.4-174.3 ${ }^{\circ} \mathrm{C}$; yield $80 \%$; ${ }^{1} \mathrm{H}$ NMR $(400 \mathrm{MHz}$, $\left.\mathrm{CDCl}_{3}\right) \delta 7.70(1 \mathrm{H}, \mathrm{d}, J=15.5 \mathrm{~Hz}), 7.63(4 \mathrm{H}, \mathrm{s}), 6.93(1 \mathrm{H}, \mathrm{d}, J=$ 
$15.4 \mathrm{~Hz}), 5.67(1 \mathrm{H}, \mathrm{s}), 3.69(8 \mathrm{H}, \mathrm{m}), 3.26-3.15(1 \mathrm{H}, \mathrm{m}), 2.77(1 \mathrm{H}$, $\mathrm{d}, J=13.6 \mathrm{~Hz}), 2.33(1 \mathrm{H}, \mathrm{s}), 2.29(1 \mathrm{H}, \mathrm{d}, J=12.0 \mathrm{~Hz}), 2.06-1.94$ $(3 \mathrm{H}, \mathrm{m}), 1.85(1 \mathrm{H}, \mathrm{d}, J=13.1 \mathrm{~Hz}), 1.68-1.61(5 \mathrm{H}, \mathrm{m}), 1.47-1.41$ $(5 \mathrm{H}, \mathrm{m}), 1.36(3 \mathrm{H}, \mathrm{s}), 1.32(1 \mathrm{H}, \mathrm{s}), 1.24(3 \mathrm{H}, \mathrm{s}), 1.19(1 \mathrm{H}, \mathrm{d}, J=$ $12.8 \mathrm{~Hz}), 1.12(3 \mathrm{H}, \mathrm{s}), 1.11(3 \mathrm{H}, \mathrm{s}), 1.05(1 \mathrm{H}, \mathrm{s}), 1.00(3 \mathrm{H}, \mathrm{s}), 0.97-$ $0.92(1 \mathrm{H}, \mathrm{m}), 0.81(3 \mathrm{H}, \mathrm{s}), 0.80(3 \mathrm{H}, \mathrm{s}), 0.69(1 \mathrm{H}, \mathrm{d}, J=11.4 \mathrm{~Hz})$; ${ }^{13} \mathrm{C}$ NMR $\left(101 \mathrm{MHz}, \mathrm{CDCl}_{3}\right) \delta 200.01,174.32,169.22,165.07$, $141.68,138.49,128.61,127.93$ (2C), 127.85, 125.78 (2C, q, $J=4.0$ $\mathrm{Hz}), 123.83$ (d, $J=272.7 \mathrm{~Hz}), 119.09$, 78.73, 61.81, 54.97, 48.13, $45.28,43.98$ (2C), 43.87 (2C), 43.30, 39.16, 39.12, 37.71, 37.11, $33.13,32.83$, 31.80 (2C), 28.39, 28.09, 27.30, 27.03, 26.74, 26.41, 23.14 (2C), 18.69, 17.49, 16.35, 15.56; HRMS (ESI): $m / z$ calcd for $\mathrm{C}_{44} \mathrm{H}_{60} \mathrm{~F}_{3} \mathrm{~N}_{2} \mathrm{O}_{4}[\mathrm{M}+\mathrm{H}]^{+} 737.4505$, found 737.4526.

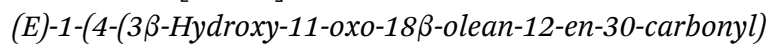
piperazin-1-yl)-3-(4-(methoxy)phenyl)-2-propen-1-one (4f). White solid; mp 1172.3-174.2 ${ }^{\circ} \mathrm{C}$; yield $80 \%$; ${ }^{1} \mathrm{H}$ NMR $(400 \mathrm{MHz}$, $\left.\mathrm{CDCl}_{3}\right) \delta 7.66(1 \mathrm{H}, \mathrm{d}, J=15.3 \mathrm{~Hz}), 7.48(2 \mathrm{H}, \mathrm{d}, J=8.7 \mathrm{~Hz}), 6.90$ $(2 \mathrm{H}, \mathrm{d}, J=8.7 \mathrm{~Hz}), 6.72(1 \mathrm{H}, \mathrm{d}, J=15.4 \mathrm{~Hz}), 5.69(1 \mathrm{H}, \mathrm{s}), 3.83$ $(3 \mathrm{H}, \mathrm{s}), 3.68(8 \mathrm{H}, \mathrm{m}), 3.26-3.16(1 \mathrm{H}, \mathrm{m}), 2.78(1 \mathrm{H}, \mathrm{d}, J=13.4 \mathrm{~Hz})$, $2.32(2 \mathrm{H}, \mathrm{d}, J=13.2 \mathrm{~Hz}), 2.08-1.98(3 \mathrm{H}, \mathrm{m}), 1.86-1.81(1 \mathrm{H}, \mathrm{m})$, 1.65-1.57 (5H, m), 1.47-1.42 (4H, m), $1.36(3 \mathrm{H}, \mathrm{s}), 1.31(1 \mathrm{H}, \mathrm{s})$, $1.24(3 \mathrm{H}, \mathrm{s}), 1.18(2 \mathrm{H}, \mathrm{d}, J=16.1 \mathrm{~Hz}), 1.13(3 \mathrm{H}, \mathrm{s}), 1.12(3 \mathrm{H}, \mathrm{s})$, $1.04(1 \mathrm{H}, \mathrm{s}), 1.00(3 \mathrm{H}, \mathrm{s}), 0.96(1 \mathrm{H}, \mathrm{d}, J=14.9 \mathrm{~Hz}), 0.82(3 \mathrm{H}, \mathrm{s})$, $0.80(3 \mathrm{H}, \mathrm{s}), 0.69(1 \mathrm{H}, \mathrm{d}, J=11.4 \mathrm{~Hz}) ;{ }^{13} \mathrm{C}$ NMR $(101 \mathrm{MHz}$, $\left.\mathrm{CDCl}_{3}\right) \delta 200.06,174.27,169.14,165.85,160.92,143.28,129.45$ (2C), 128.60, 127.72, 114.23 (2C), 113.85, 78.76, 61.79, 55.36, 54.93, 48.05, 45.27, 43.96 (2C), 43.91 (2C), 43.28, 39.12 (2C), $37.73,37.08,33.00,32.81,31.78$ (2C), 28.40, 28.08, 27.29, 27.06, 26.71, 26.39, 23.16 (2C), 18.68, 17.48, 16.37, 15.57; HRMS (ESI): $m / z$ calcd for $\mathrm{C}_{44} \mathrm{H}_{63} \mathrm{~N}_{2} \mathrm{O}_{5}[\mathrm{M}+\mathrm{H}]^{+} 699.4737$, found 699.4765.

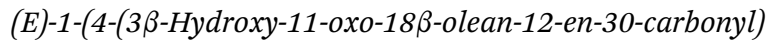
piperazin-1-yl)-3-(3,4,5-(trimethoxy)phenyl)-2-propen-1-one (4g). White solid; mp 1163.2-164.8 ${ }^{\circ} \mathrm{C}$; yield 63\%; ${ }^{1} \mathrm{H}$ NMR $(400 \mathrm{MHz}$, $\left.\mathrm{CDCl}_{3}\right) \delta 7.62(1 \mathrm{H}, \mathrm{d}, J=15.3 \mathrm{~Hz}), 6.72(3 \mathrm{H}, \mathrm{d}, J=17.7 \mathrm{~Hz}), 5.68$ $(1 \mathrm{H}, \mathrm{s}), 3.90(6 \mathrm{H}, \mathrm{s}), 3.88(3 \mathrm{H}, \mathrm{s}), 3.70(8 \mathrm{H}, \mathrm{m}), 3.22(1 \mathrm{H}, \mathrm{m}), 2.78$ $(1 \mathrm{H}, \mathrm{d}, J=13.2 \mathrm{~Hz}), 2.34(1 \mathrm{H}, \mathrm{s}), 2.29(1 \mathrm{H}, \mathrm{d}, J=16.0 \mathrm{~Hz}), 2.10-$ $1.98(3 \mathrm{H}, \mathrm{m}), 1.87-1.82(1 \mathrm{H}, \mathrm{m}), 1.71-1.60(5 \mathrm{H}, \mathrm{m}), 1.48-1.41$ $(5 \mathrm{H}, \mathrm{m}), 1.37$ (3H, s), $1.25(3 \mathrm{H}, \mathrm{s}), 1.20(2 \mathrm{H}, \mathrm{d}, J=15.3 \mathrm{~Hz}), 1.13$ $(3 \mathrm{H}, \mathrm{s}), 1.12(3 \mathrm{H}, \mathrm{s}), 1.05(1 \mathrm{H}, \mathrm{s}), 1.00(3 \mathrm{H}, \mathrm{s}), 0.96(1 \mathrm{H}, \mathrm{d}, J=10.7$ $\mathrm{Hz}), 0.82(3 \mathrm{H}, \mathrm{s}), 0.81(3 \mathrm{H}, \mathrm{s}), 0.70(1 \mathrm{H}, \mathrm{d}, J=11.1 \mathrm{~Hz}) ;{ }^{13} \mathrm{C} \mathrm{NMR}$ $\left(101 \mathrm{MHz}, \mathrm{CDCl}_{3}\right) \delta 200.06,174.30,169.28,165.68,153.42(2 \mathrm{C})$, 143.64, 139.84, 130.54, 128.60, 115.65, 105.15 (2C), 78.73, 61.81, 60.94, 56.23 (2C), 54.96, 48.14, 45.28, 43.98 (2C), 43.85 (2C), $43.30,39.15,39.11,37.71,37.10,33.14,32.82,31.79$ (2C), 28.39, 28.08, 27.29, 27.03, 26.74, 26.41, 23.14 (2C), 18.69, 17.48, 16.35, 15.55; HRMS (ESI): $m / z$ calcd for $\mathrm{C}_{46} \mathrm{H}_{67} \mathrm{~N}_{2} \mathrm{O}_{7}[\mathrm{M}+\mathrm{H}]^{+}$759.4948, found 759.4978 .

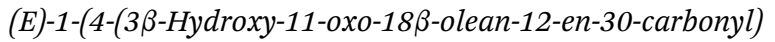
piperazin-1-yl)-2-methyl-3-phenyl-2-propen-1-one (4h). White solid; mp 1145.3-146.6 ${ }^{\circ} \mathrm{C}$; yield $80 \%$; ${ }^{1} \mathrm{H}$ NMR $(400 \mathrm{MHz}$, $\left.\mathrm{CDCl}_{3}\right) \delta ; 7.40-7.29(5 \mathrm{H}, \mathrm{m}), 6.56(1 \mathrm{H}, \mathrm{s}), 5.68(1 \mathrm{H}, \mathrm{s}), 3.69-3.62$ $(8 \mathrm{H}, \mathrm{m}), 3.21(1 \mathrm{H}, \mathrm{dd}, J=10.2,5.1 \mathrm{~Hz}), 2.78(1 \mathrm{H}, \mathrm{d}, J=13.3 \mathrm{~Hz})$, $2.33(1 \mathrm{H}, \mathrm{s}), 2.29(1 \mathrm{H}, \mathrm{d}, J=11.5 \mathrm{~Hz}), 2.11(3 \mathrm{H}, \mathrm{s}), 2.05-1.96(3 \mathrm{H}$, $\mathrm{m}), 1.87-1.80(1 \mathrm{H}, \mathrm{m}), 1.69-1.59(6 \mathrm{H}, \mathrm{m}), 1.48-1.38(5 \mathrm{H}, \mathrm{m})$, $1.36(3 \mathrm{H}, \mathrm{s}), 1.24(3 \mathrm{H}, \mathrm{s}), 1.19(1 \mathrm{H}, \mathrm{d}, J=13.9 \mathrm{~Hz}), 1.13(3 \mathrm{H}, \mathrm{s})$, $1.11(3 \mathrm{H}, \mathrm{s}), 1.05(1 \mathrm{H}, \mathrm{s}), 1.00(3 \mathrm{H}, \mathrm{s}), 0.95(1 \mathrm{H}, \mathrm{d}, J=14.3 \mathrm{~Hz})$, $0.81(3 \mathrm{H}, \mathrm{s}), 0.80(3 \mathrm{H}, \mathrm{s}), 0.69(1 \mathrm{H}, \mathrm{d}, J=11.1 \mathrm{~Hz}) ;{ }^{13} \mathrm{C}$ NMR $(101$
$\left.\mathrm{MHz}, \mathrm{CDCl}_{3}\right) \delta 200.05,174.28,172.59,169.27,135.57,132.23$, 130.41, 129.02 (2C), 128.57, 128.36 (2C), 127.64, 78.72, 61.77, 54.93, 48.10, 45.26, 43.92 (2C), 43.82 (2C), 43.27, 39.10 (2C), 37.69, 37.06, 33.12, 32.79, 31.77 (2C), 28.37, 28.07, 27.26, 27.03, 26.69, 26.39, 23.12 (2C), 18.66, 17.46, 16.34, 16.20, 15.56; HRMS (ESI): $m / z$ calcd for $\mathrm{C}_{44} \mathrm{H}_{63} \mathrm{~N}_{2} \mathrm{O}_{4}[\mathrm{M}+\mathrm{H}]^{+}$683.4788, found 683.4813.

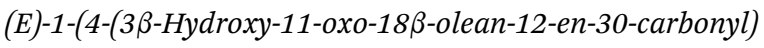
piperazin-1-yl)-3-phenylpropyl-1-one (4i). White solid; mp 134.8$136.1{ }^{\circ} \mathrm{C}$; yield $63 \% ;{ }^{1} \mathrm{H}$ NMR $\left(400 \mathrm{MHz}, \mathrm{CDCl}_{3}\right) \delta 7.27(2 \mathrm{H}, \mathrm{d}, J=$ $7.0 \mathrm{~Hz}), 7.20(3 \mathrm{H}, \mathrm{d}, J=7.1 \mathrm{~Hz}), 5.64(1 \mathrm{H}, \mathrm{s}), 3.60-3.34(8 \mathrm{H}, \mathrm{m})$, $3.22-3.18(1 \mathrm{H}, \mathrm{m}), 3.10-3.02(1 \mathrm{H}, \mathrm{m}), 2.96(2 \mathrm{H}, \mathrm{t}, J=7.6 \mathrm{~Hz})$, $2.76(1 \mathrm{H}, \mathrm{d}, J=13.5 \mathrm{~Hz}), 2.62(2 \mathrm{H}, \mathrm{t}, J=7.6 \mathrm{~Hz}), 2.31(1 \mathrm{H}, \mathrm{s})$, $2.25(1 \mathrm{H}, \mathrm{d}, J=12.2 \mathrm{~Hz}), 2.07-1.91(3 \mathrm{H}, \mathrm{m}), 1.86-1.77(1 \mathrm{H}, \mathrm{m})$, 1.64-1.56 (5H, m), 1.46-1.37 (5H, m), 1.34 (3H, s), 1.19 (3H, s), $1.15(1 \mathrm{H}, \mathrm{s}), 1.11(3 \mathrm{H}, \mathrm{s}), 1.09(3 \mathrm{H}, \mathrm{s}), 1.02(1 \mathrm{H}, \mathrm{s}), 0.98(3 \mathrm{H}, \mathrm{s})$, $0.94(1 \mathrm{H}, \mathrm{d}, J=12.5 \mathrm{~Hz}), 0.78(6 \mathrm{H}, \mathrm{s}), 0.68(1 \mathrm{H}, \mathrm{d}, J=11.5 \mathrm{~Hz})$; ${ }^{13} \mathrm{C}$ NMR $\left(101 \mathrm{MHz}, \mathrm{CDCl}_{3}\right) \delta 200.00,174.14,170.89,169.25$, 140.85, 128.49 (2C), 128.38 (2C), 128.36, 126.24, 78.62, 61.71, 54.86, 47.99, 45.41, 45.20, 43.82 (2C), 43.75 (2C), 43.20, 41.56, $39.05,37.62,37.00,34.85,32.96,32.73,31.69,31.39,28.32$, 28.03, 27.20, 26.93, 26.62, 26.32, 23.08 (2C), 18.60, 17.40, 16.30, 15.54; HRMS (ESI): $m / z$ calcd for $\mathrm{C}_{43} \mathrm{H}_{63} \mathrm{~N}_{2} \mathrm{O}_{4}[\mathrm{M}+\mathrm{H}]^{+} 671.4788$, found 671.4811 .

4.1.3 General procedure for the synthesis of 6a-6i. Anhydrous methanol ( $1 \mathrm{~mL}, 25 \mathrm{mmol})$ was added slowly into the solution of cinnamic acid chloride (prepared as described above) in dry dichloromethane $(10 \mathrm{~mL})$ and reacted at room temperature for $0.5 \mathrm{~h}$. Then the solvent was evaporated in vacuo to give the crude product, which was not purified for further reaction. The product was dissolved in ethylenediamine and reacted under reflux for $2 \mathrm{~h}$. After the reaction was finished, the solution was extracted with ethyl acetate $(3 \times)$ and washed by saturated brine $(3 \times)$. The organic layer was dried over anhydrous magnesium sulphate, filtered and evaporated. Purification was performed using column chromatography (dichloromethane/methanol $=50 / 1$ ) to give the desired product 6a-6i.

$\mathrm{N}$-(2-Aminoethyl)cinnamamide (6a). Yellow oil; yield $52 \% ;{ }^{1} \mathrm{H}$ NMR (500 MHz, $d_{6}$-DMSO) $\delta 8.12(1 \mathrm{H}, \mathrm{s}), 7.55(2 \mathrm{H}, \mathrm{d}, J=7.1 \mathrm{~Hz})$, $7.42-7.34(4 \mathrm{H}, \mathrm{m}), 6.63(1 \mathrm{H}, \mathrm{d}, J=15.8 \mathrm{~Hz}), 3.19(2 \mathrm{H}, \mathrm{dd}, J=$ 12.2, 6.2 Hz), $2.65(2 \mathrm{H}, \mathrm{t}, J=6.4 \mathrm{~Hz}), 1.22(1 \mathrm{H}, \mathrm{s})$; LC-MS: [M + $\mathrm{H}]^{+} 191.1$.

(E)-N-(2-Aminoethyl)-3-(4-fluorophenyl)acrylamide (6b). Yellow oil; yield 61\%; ${ }^{1} \mathrm{H}$ NMR (500 MHz, $d_{6}$-DMSO) $\delta 8.52(1 \mathrm{H}, \mathrm{t}, J=5.5$ $\mathrm{Hz}), 7.64(2 \mathrm{H}, \mathrm{dd}, J=8.7,5.6 \mathrm{~Hz}), 7.47(1 \mathrm{H}, \mathrm{d}, J=15.9 \mathrm{~Hz}), 7.26$ $(2 \mathrm{H}, \mathrm{t}, J=8.8 \mathrm{~Hz}), 6.60(1 \mathrm{H}, \mathrm{d}, J=15.9 \mathrm{~Hz}), 3.42(2 \mathrm{H}, \mathrm{dd}, J=$ 12.1, $6.1 \mathrm{~Hz}), 2.90(2 \mathrm{H}, \mathrm{t}, J=6.2 \mathrm{~Hz}), 1.23(2 \mathrm{H}, \mathrm{s})$; LC-MS: [M + $\mathrm{H}]^{+} 209.1$.

(E)-N-(2-Aminoethyl)-3-(4-chlorophenyl)acrylamide (6c). Yellow oil; yield 51\%; ${ }^{1} \mathrm{H}$ NMR $\left(500 \mathrm{MHz}, d_{6}\right.$-DMSO) $\delta 8.16(1 \mathrm{H}, \mathrm{t}, J=5.4$ $\mathrm{Hz}), 7.58(2 \mathrm{H}, \mathrm{d}, J=8.5 \mathrm{~Hz}), 7.46(2 \mathrm{H}, \mathrm{d}, J=8.5 \mathrm{~Hz}), 7.40(1 \mathrm{H}, \mathrm{d}$, $J=15.8 \mathrm{~Hz}), 6.63(1 \mathrm{H}, \mathrm{d}, J=15.8 \mathrm{~Hz}), 3.21(2 \mathrm{H}, \mathrm{dd}, J=12.2,6.2$ $\mathrm{Hz}), 2.67(2 \mathrm{H}, \mathrm{t}, J=6.4 \mathrm{~Hz}), 1.22(2 \mathrm{H}, \mathrm{s})$; LC-MS: [M + H $]^{+} 225.2$.

(E)-N-(2-Aminoethyl)-3-(p-tolyl)acrylamide (6d). Yellow oil; yield $56 \%$; ${ }^{1} \mathrm{H}$ NMR $\left(500 \mathrm{MHz}, d_{6}\right.$-DMSO) $\delta 8.08(1 \mathrm{H}, \mathrm{t}, J=5.3$ $\mathrm{Hz}), 7.43(2 \mathrm{H}, \mathrm{d}, J=8.0 \mathrm{~Hz}), 7.36(1 \mathrm{H}, \mathrm{d}, J=15.8 \mathrm{~Hz}), 7.21(2 \mathrm{H}$, 
$\mathrm{d}, J=7.9 \mathrm{~Hz}), 6.57(1 \mathrm{H}, \mathrm{d}, J=15.8 \mathrm{~Hz}), 3.18(2 \mathrm{H}, \mathrm{dd}, J=12.2,6.2$ $\mathrm{Hz}), 2.64(2 \mathrm{H}, \mathrm{t}, J=6.4 \mathrm{~Hz}), 2.31(3 \mathrm{H}, \mathrm{s}), 1.22(2 \mathrm{H}, \mathrm{s})$; LC-MS: [M $+\mathrm{H}]^{+} 205.1$.

(E)-N-(2-Aminoethyl)-3-(4-(trifluoromethyl)phenyl)acrylamide (6e). Yellow oil; yield $60 \% ;{ }^{1} \mathrm{H}$ NMR (500 MHz, $d_{6}$-DMSO) $\delta 8.59$ $(1 \mathrm{H}, \mathrm{t}, J=5.6 \mathrm{~Hz}), 7.84-7.76(4 \mathrm{H}, \mathrm{m}), 7.54(1 \mathrm{H}, \mathrm{d}, J=15.9 \mathrm{~Hz})$, $6.78(1 \mathrm{H}, \mathrm{d}, J=15.9 \mathrm{~Hz}), 3.43(2 \mathrm{H}, \mathrm{q}, J=6.1 \mathrm{~Hz}), 2.91(2 \mathrm{H}, \mathrm{t}, J=$ $6.3 \mathrm{~Hz}), 1.23(2 \mathrm{H}, \mathrm{s})$; LC-MS: [M + H $]^{+}$259.2.

(E)-N-(2-Aminoethyl)-3-(4-methoxyphenyl)acrylamide

(6f). Yellow oil; yield 68\%; ${ }^{1} \mathrm{H}$ NMR $\left(500 \mathrm{MHz}, d_{6}\right.$-DMSO) $\delta 8.03(1 \mathrm{H}$, m), $7.49(2 \mathrm{H}, \mathrm{d}, J=8.7 \mathrm{~Hz}), 7.35(1 \mathrm{H}, \mathrm{d}, J=15.8 \mathrm{~Hz}), 6.96(2 \mathrm{H}, \mathrm{d}$, $J=8.7 \mathrm{~Hz}), 6.47(1 \mathrm{H}, \mathrm{d}, J=15.8 \mathrm{~Hz}), 3.77(3 \mathrm{H}, \mathrm{s}), 3.20-3.17(2 \mathrm{H}$, $\mathrm{m}), 2.66-2.62(2 \mathrm{H}, \mathrm{m}), 1.22(2 \mathrm{H}, \mathrm{s})$; LC-MS: [M + H $]^{+} 221.1$.

(E)-N-(2-Aminoethyl)-3-(3,4,5-trimethoxyphenyl)acrylamide (6g). Yellow oil; yield 52\%; ${ }^{1} \mathrm{H}$ NMR (500 MHz, $d_{6}$-DMSO) $\delta 8.04$ $(1 \mathrm{H}, \mathrm{t}, J=5.5 \mathrm{~Hz}), 7.35(1 \mathrm{H}, \mathrm{d}, J=15.7 \mathrm{~Hz}), 6.88(2 \mathrm{H}, \mathrm{s}), 6.58$ $(1 \mathrm{H}, \mathrm{d}, J=15.7 \mathrm{~Hz}), 3.80(6 \mathrm{H}, \mathrm{s}), 3.67(3 \mathrm{H}, \mathrm{s}), 3.21-3.17(2 \mathrm{H}, \mathrm{m})$, $2.65(2 \mathrm{H}, \mathrm{m}), 1.22(2 \mathrm{H}, \mathrm{s})$; LC-MS: $[\mathrm{M}+\mathrm{H}]^{+} 281.1$.

(E)-N-(2-Aminoethyl)-2-methyl-3-phenylacrylamide (6h). Yellow oil; yield 54\%; ${ }^{1} \mathrm{H}$ NMR (500 MHz, $d_{6}$-DMSO) $\delta 8.06(1 \mathrm{H}, \mathrm{t}, J=5.0$ $\mathrm{Hz}), 7.50-7.27(5 \mathrm{H}, \mathrm{m}), 7.24(1 \mathrm{H}, \mathrm{s}), 3.53(1 \mathrm{H}, \mathrm{s}), 3.23(1 \mathrm{H}, \mathrm{dd}, J$ $=12.1,6.2 \mathrm{~Hz}), 2.72(1 \mathrm{H}, \mathrm{t}, J=6.4 \mathrm{~Hz}), 2.00(3 \mathrm{H}, \mathrm{d}, J=1.2 \mathrm{~Hz})$, 1.22 (2H, s); LC-MS: $[\mathrm{M}+\mathrm{H}]^{+} 205.1$.

$\mathrm{N}$-(2-Aminoethyl)-3-phenylpropanamide (6i). Yellow oil; yield $59 \%$; 1H NMR (500 MHz, $d_{6}$-DMSO) $\delta 8.23$ (1H, s), 7.30-7.11 (5H, m), 3.27-3.24 (2H, m), 2.82-2.76 (4H, m), 2.41-2.38 $(2 \mathrm{H}$, m), 1.22 (2H, s); LC-MS: [M + H]+193.1.

4.1.4 General procedure for the synthesis of 7a-7i. GA (100 mg, $0.21 \mathrm{mmol}$ ) was dissolved in DMF $(10 \mathrm{~mL})$, HATU (100 $\mathrm{mg}, 0.26 \mathrm{mmol})$ and DIPEA $(0.16 \mathrm{~mL}, 0.88 \mathrm{mmol})$ were added and the mixture was stirred at room temperature for $0.5 \mathrm{~h}$. Then compound $\mathbf{6 a - 6 \mathbf { i }}$ were added into the resulting solution and reacted at room temperature for $5 \mathrm{~h}$. Upon completion, the mixture was poured into water and filtered under reduced pressure to obtain the crude product. Purification was performed using preparative TLC (dichloromethane/ methanol $=30 / 1)$ to give the desired product $7 \mathbf{a}-7 \mathbf{i}$.

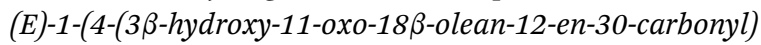
ethanediamine-1-yl)-3-phenyl-2-propen-1-one (7a). White solid; mp 168.9-170.1 ${ }^{\circ} \mathrm{C}$; yield 68\%; ${ }^{1} \mathrm{H}$ NMR $\left(400 \mathrm{MHz}, \mathrm{CDCl}_{3}\right) \delta 7.61$ $(1 \mathrm{H}, \mathrm{d}, J=15.8 \mathrm{~Hz}), 7.50-7.49(2 \mathrm{H}, \mathrm{m}), 7.34-7.33(3 \mathrm{H}, \mathrm{m}), 6.68$ $(1 \mathrm{H}, \mathrm{s}), 6.58(1 \mathrm{H}, \mathrm{s}), 6.42(1 \mathrm{H}, \mathrm{d}, J=14.7 \mathrm{~Hz}), 5.72(1 \mathrm{H}, \mathrm{s}), 3.62-$ $3.36(4 \mathrm{H}, \mathrm{m}), 3.23-3.20(1 \mathrm{H}, \mathrm{m}), 2.77(1 \mathrm{H}, \mathrm{d}, J=13.0 \mathrm{~Hz}), 2.30$ $(1 \mathrm{H}, \mathrm{s}), 2.12(1 \mathrm{H}, \mathrm{d}, J=10.7 \mathrm{~Hz}), 2.07-1.95(1 \mathrm{H}, \mathrm{m}), 1.88(2 \mathrm{H}, \mathrm{d}, J$ $=9.1 \mathrm{~Hz}), 1.83-1.72(2 \mathrm{H}, \mathrm{m}), 1.67-1.56(7 \mathrm{H}, \mathrm{m}), 1.45-1.37(4 \mathrm{H}$, $\mathrm{m}), 1.35(3 \mathrm{H}, \mathrm{s}), 1.16(1 \mathrm{H}, \mathrm{s}), 1.11(6 \mathrm{H}, \mathrm{s}), 1.01(3 \mathrm{H}, \mathrm{s}), 0.99(3 \mathrm{H}$, s), $0.90(1 \mathrm{H}, \mathrm{s}), 0.80(3 \mathrm{H}, \mathrm{s}), 0.74(3 \mathrm{H}, \mathrm{s}), 0.68(1 \mathrm{H}, \mathrm{d}, J=9.9 \mathrm{~Hz})$; ${ }^{13} \mathrm{C}$ NMR (101 MHz, $\mathrm{CDCl}_{3}$ ) $\delta$ 200.02, 177.53, 169.18, 167.25, 141.46, 134.65, 129.69, 128.79 (2C), 128.51, 127.89 (2C), 120.30, $78.75,61.78,54.94,48.04,45.32,43.64,43.18,41.56,40.67$, $40.19,39.17,39.12,37.56,37.08,32.74,31.84,31.42,29.48$, $28.43,28.10,27.28,26.46,26.43,23.36,18.57,17.46,16.35$, 15.58; HRMS (ESI): $m / z$ calcd for $\mathrm{C}_{41} \mathrm{H}_{59} \mathrm{~N}_{2} \mathrm{O}_{4}[\mathrm{M}+\mathrm{H}]^{+}$643.4475, found 643.4500 .

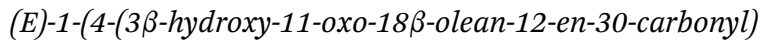
ethanediamine-1-yl)-3-(4-(fluoro)phenyl)-2-propen-1-one (7b). White solid; mp 178.2-179.3 ${ }^{\circ} \mathrm{C}$; yield 50\%; ${ }^{1} \mathrm{H}$ NMR $(400 \mathrm{MHz}$,
$\left.\mathrm{CDCl}_{3}\right) \delta 7.57(1 \mathrm{H}, \mathrm{d}, J=15.5 \mathrm{~Hz}), 7.53-7.43(2 \mathrm{H}, \mathrm{m}), 7.03(2 \mathrm{H}, \mathrm{t}$, $J=8.4 \mathrm{~Hz}), 6.65(2 \mathrm{H}, \mathrm{s}), 6.34(1 \mathrm{H}, \mathrm{d}, J=15.5 \mathrm{~Hz}), 5.71(1 \mathrm{H}, \mathrm{s})$, $3.65-3.36(4 \mathrm{H}, \mathrm{m}), 3.21(1 \mathrm{H}, \mathrm{dd}, J=10.2,5.0 \mathrm{~Hz}), 2.76(1 \mathrm{H}, \mathrm{d}, J=$ $13.3 \mathrm{~Hz}), 2.30(1 \mathrm{H}, \mathrm{s}), 2.10(1 \mathrm{H}, \mathrm{d}, J=12.3 \mathrm{~Hz}), 2.01(1 \mathrm{H}, \mathrm{dd}, J=$ 12.9, $9.1 \mathrm{~Hz}), 1.88(2 \mathrm{H}, \mathrm{d}, J=14.1 \mathrm{~Hz}), 1.77(1 \mathrm{H}, \mathrm{dd}, J=14.3$, $10.7 \mathrm{~Hz}), 1.68-1.60$ (6H, m), 1.42-1.38 (5H, m), 1.35 (3H, s), 1.18 $(1 \mathrm{H}, \mathrm{s}), 1.11(6 \mathrm{H}, \mathrm{s}), 0.99(6 \mathrm{H}, \mathrm{s}), 0.94(2 \mathrm{H}, \mathrm{d}, J=8.2 \mathrm{~Hz}), 0.80$ $(3 \mathrm{H}, \mathrm{s}), 0.73(3 \mathrm{H}, \mathrm{s}), 0.67(1 \mathrm{H}, \mathrm{d}, J=11.2 \mathrm{~Hz}) ;{ }^{13} \mathrm{C}$ NMR (101 $\mathrm{MHz}, d_{6}$-DMSO) $\delta 199.11,175.54,169.60,165.19,162.68(\mathrm{~d}, J=$ $247.4 \mathrm{~Hz}$ ), 137.65, 131.54 (d, $J=3.0 \mathrm{~Hz}), 129.71$ (2C, d, $J=8.1$ $\mathrm{Hz}), 127.67,122.05,115.86$ (2C, d, $J=22.2 \mathrm{~Hz}$ ), 76.66, 61.20, 54.18, 47.54, 44.82, 43.00 (2C), 42.88, 40.80, 38.84, 38.62, 37.31, $36.70,32.20,31.45$ (2C), 30.43, 28.84, 28.22, 28.20, 27.03, 26.10, 26.03, 23.10, 18.24, 17.21, 16.15, 16.06; HRMS (ESI): $\mathrm{m} / \mathrm{z}$ calcd for $\mathrm{C}_{41} \mathrm{H}_{58} \mathrm{FN}_{2} \mathrm{O}_{4}[\mathrm{M}+\mathrm{H}]^{+}$661.4381, found 661.4402.

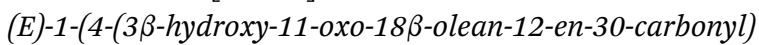
ethanediamine-1-yl)-3-(4-(chloro)phenyl)-2-propen-1-one (7c). White solid; mp 164.7-166.2 ${ }^{\circ} \mathrm{C}$; yield 70\%; ${ }^{1} \mathrm{H}$ NMR $(400 \mathrm{MHz}$, $\left.\mathrm{CDCl}_{3}\right) \delta 7.54(1 \mathrm{H}, \mathrm{d}, J=15.3 \mathrm{~Hz}), 7.41(2 \mathrm{H}, \mathrm{d}, J=8.0 \mathrm{~Hz}), 7.30$ $(2 \mathrm{H}, \mathrm{d}, J=8.0 \mathrm{~Hz}), 6.90(1 \mathrm{H}, \mathrm{s}), 6.81(1 \mathrm{H}, \mathrm{s}), 6.42(1 \mathrm{H}, \mathrm{d}, J=15.5$ $\mathrm{Hz}), 5.69$ (1H, s), 3.63-3.36 (4H, m), $3.21(1 \mathrm{H}, \mathrm{dd}, J=10.0,4.6$ $\mathrm{Hz}), 2.74(1 \mathrm{H}, \mathrm{d}, J=13.4 \mathrm{~Hz}), 2.29(1 \mathrm{H}, \mathrm{s}), 2.08(1 \mathrm{H}, \mathrm{d}, J=13.8$ $\mathrm{Hz}), 1.98(1 \mathrm{H}, \mathrm{d}, J=14.2 \mathrm{~Hz}), 1.89(2 \mathrm{H}, \mathrm{d}, J=11.9 \mathrm{~Hz}), 1.81-1.71$ (2H, m), 1.66-1.56 (6H, m), 1.43-1.35 (5H, m), 1.34 (3H, s), 1.16 $(1 \mathrm{H}, \mathrm{s}), 1.10(6 \mathrm{H}, \mathrm{s}), 0.99(3 \mathrm{H}, \mathrm{s}), 0.97(3 \mathrm{H}, \mathrm{s}), 0.89(1 \mathrm{H}, \mathrm{d}, J=18.5$ $\mathrm{Hz}), 0.79(3 \mathrm{H}, \mathrm{s}), 0.71(3 \mathrm{H}, \mathrm{s}), 0.66(1 \mathrm{H}, \mathrm{d}, J=11.3 \mathrm{~Hz}) ;{ }^{13} \mathrm{C} \mathrm{NMR}$ (101 MHz, $d_{6}$-DMSO) $\delta 199.06,175.53,169.54,165.02,137.46$, 133.83, 133.80, 129.22 (2C), 128.91 (2C), 127.65, 122.93, 76.64, 61.18, 54.16, 47.51, 44.79, 42.97, 42.86, 40.79, 38.88, 38.81, $38.59,37.29,36.68,32.18,31.43$ (2C), 30.40, 28.82, 28.18 (2C), 27.01, 26.08, 26.02, 23.07, 18.21, 17.19, 16.12, 16.03; HRMS (ESI): $m / z$ calcd for $\mathrm{C}_{41} \mathrm{H}_{58} \mathrm{ClN}_{2} \mathrm{O}_{4}[\mathrm{M}+\mathrm{H}]^{+} 677.4085$, found 677.4112 .

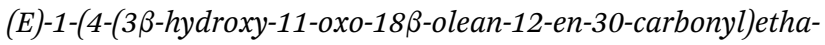
nediamine-1-yl)-3-(p-tolyl)-2-propen-1-one (7d). White solid; $\mathrm{mp}$ 166.8-169.1 ${ }^{\circ} \mathrm{C}$; yield 52\%; ${ }^{1} \mathrm{H}$ NMR (400 MHz, $d_{6}$-DMSO) $\delta 8.02$ $(1 \mathrm{H}, \mathrm{s}), 7.65(1 \mathrm{H}, \mathrm{s}), 7.41(2 \mathrm{H}, \mathrm{d}, J=8.0 \mathrm{~Hz}), 7.34(1 \mathrm{H}, \mathrm{d}, J=15.7$ $\mathrm{Hz}), 7.17(2 \mathrm{H}, \mathrm{d}, J=7.8 \mathrm{~Hz}), 6.51(1 \mathrm{H}, \mathrm{d}, J=15.7 \mathrm{~Hz}), 5.53(1 \mathrm{H}$, s), $4.31(1 \mathrm{H}, \mathrm{d}, J=5.0 \mathrm{~Hz}), 3.19-3.16(4 \mathrm{H}, \mathrm{m}), 2.98(1 \mathrm{H}, \mathrm{m}), 2.58$ $(1 \mathrm{H}, \mathrm{d}, J=13.2 \mathrm{~Hz}), 2.29(3 \mathrm{H}, \mathrm{s}), 2.27(1 \mathrm{H}, \mathrm{s}), 2.07-2.00(2 \mathrm{H}, \mathrm{m})$, 1.88-1.86 (1H, m), 1.79-1.75 (1H, m), 1.71-1.63 (1H, m), 1.62$1.55(2 \mathrm{H}, \mathrm{m}), 1.52-1.46(2 \mathrm{H}, \mathrm{m}), 1.40-1.37(1 \mathrm{H}, \mathrm{m}), 1.31(3 \mathrm{H}, \mathrm{s})$, 1.29-1.18 (6H, m), $1.09(1 \mathrm{H}, \mathrm{d}, J=8.4 \mathrm{~Hz}), 1.02(1 \mathrm{H}, \mathrm{s}), 0.99(6 \mathrm{H}$, s), $0.89(3 \mathrm{H}, \mathrm{s}), 0.89(3 \mathrm{H}, \mathrm{s}), 0.84(1 \mathrm{H}, \mathrm{s}), 0.67(6 \mathrm{H}, \mathrm{s}) ;{ }^{13} \mathrm{C} \mathrm{NMR}$ (101 MHz, $d_{6}$-DMSO) $\delta 199.12,175.57,169.61,165.45,139.12$, 138.82, 132.16, 129.53 (2C), 127.69, 127.56 (2C), 121.07, 76.67, 61.23, 54.19, 47.56, 44.84, 43.01, 42.90, 40.82, 38.86, 38.68, $38.64,37.33,36.72,32.21,31.46$ (2C), 30.45, 28.86, 28.27, 28.22, $27.05,26.12,26.04,23.12,21.03,18.28,17.23,16.18,16.08$; HRMS (ESI): $m / z$ calcd for $\mathrm{C}_{42} \mathrm{H}_{61} \mathrm{~N}_{2} \mathrm{O}_{4}[\mathrm{M}+\mathrm{H}]^{+} 657.4631$, found 657.4657.

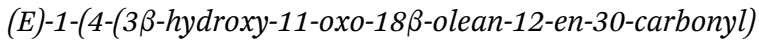
ethanediamine-1-yl)-3-(4-(trifluoromethyl)phenyl)-2-propen-1-one (7e). White solid; mp 1174.5-176.9 ${ }^{\circ} \mathrm{C}$; yield $72 \%$; ${ }^{1} \mathrm{H}$ NMR (400 $\mathrm{MHz}, d_{6}$-DMSO) $\delta 8.13(1 \mathrm{H}, \mathrm{s}), 7.75-7.69(4 \mathrm{H}, \mathrm{m}), 7.63(1 \mathrm{H}, \mathrm{s})$, $7.44(1 \mathrm{H}, \mathrm{d}, J=15.7 \mathrm{~Hz}), 6.72(1 \mathrm{H}, \mathrm{d}, J=15.9 \mathrm{~Hz}), 5.52(1 \mathrm{H}, \mathrm{s})$, $4.28(1 \mathrm{H}, \mathrm{d}, J=4.8 \mathrm{~Hz}), 3.26-3.13(4 \mathrm{H}, \mathrm{m}), 3.04-2.98(1 \mathrm{H}, \mathrm{m})$, 
$2.56(1 \mathrm{H}, \mathrm{d}, J=13.1 \mathrm{~Hz}), 2.26(1 \mathrm{H}, \mathrm{s}), 2.05-1.98(2 \mathrm{H}, \mathrm{m}), 1.88$ $(1 \mathrm{H}, \mathrm{d}, J=6.8 \mathrm{~Hz}), 1.75(1 \mathrm{H}, \mathrm{s}), 1.68(1 \mathrm{H}, \mathrm{d}, J=13.4 \mathrm{~Hz}), 1.47$ $(2 \mathrm{H}, \mathrm{d}, J=9.6 \mathrm{~Hz}), 1.39(1 \mathrm{H}, \mathrm{d}, J=11.7 \mathrm{~Hz}), 1.30(3 \mathrm{H}, \mathrm{s}), 1.27-$ $1.22(5 \mathrm{H}, \mathrm{m}), 1.08(1 \mathrm{H}, \mathrm{d}, J=13.5 \mathrm{~Hz}), 1.02(1 \mathrm{H}, \mathrm{s}), 0.99(3 \mathrm{H}, \mathrm{s})$, $0.94(3 \mathrm{H}, \mathrm{s}), 0.91(1 \mathrm{H}, \mathrm{s}), 0.88(3 \mathrm{H}, \mathrm{s}), 0.83(3 \mathrm{H}, \mathrm{s}), 0.72(1 \mathrm{H}, \mathrm{s})$, $0.66(6 \mathrm{H}, \mathrm{s}) ;{ }^{13} \mathrm{C}$ NMR (101 MHz, $d_{6}$-DMSO) $\delta 199.09,175.57$, 169.57, 164.75, 138.94, 137.17, 128.95 (d, $J=9.1 \mathrm{~Hz}), 128.19$ (2C), 127.61 (q, $J=10.1 \mathrm{~Hz}), 125.75(2 \mathrm{C}, \mathrm{q}, J=4.0 \mathrm{~Hz}), 124.92$, $124.16(\mathrm{~d}, J=273.7 \mathrm{~Hz}), 76.65,61.19,54.15,47.51,44.80,43.01$, $42.86,40.78,38.83,38.61,38.51,37.30,36.71,36.66,32.17$, $31.45,30.40,28.85,28.19,28.15,27.02,26.09,26.03,23.09$, 18.17, 17.19, 16.09, 16.03; HRMS (ESI): $\mathrm{m} / \mathrm{z}$ calcd for $\mathrm{C}_{42} \mathrm{H}_{58} \mathrm{~F}_{3} \mathrm{~N}_{2} \mathrm{O}_{4}[\mathrm{M}+\mathrm{H}]^{+}$711.4349, found 711.4374.

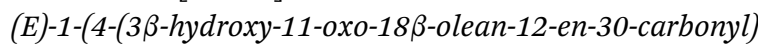
ethanediamine-1-yl)-3-(4-(methoxy)phenyl)-2-propen-1-one White solid; mp 162.9-165.3 ${ }^{\circ} \mathrm{C}$; yield 69\%; ${ }^{1} \mathrm{H}$ NMR $(400 \mathrm{MHz}$, $d_{6}$-DMSO) $\delta 7.97(1 \mathrm{H}, \mathrm{s}), 7.65(1 \mathrm{H}, \mathrm{s}), 7.47(2 \mathrm{H}, \mathrm{d}, J=8.6 \mathrm{~Hz})$, $7.33(1 \mathrm{H}, \mathrm{d}, J=15.7 \mathrm{~Hz}), 6.92(2 \mathrm{H}, \mathrm{d}, J=8.6 \mathrm{~Hz}), 6.42(1 \mathrm{H}, \mathrm{d}, J=$ $15.7 \mathrm{~Hz}), 5.53(1 \mathrm{H}, \mathrm{s}), 4.31(1 \mathrm{H}, \mathrm{d}, J=5.0 \mathrm{~Hz}), 3.76(3 \mathrm{H}, \mathrm{s}), 3.30-$ $3.04(4 \mathrm{H}, \mathrm{m}), 3.06-2.96(1 \mathrm{H}, \mathrm{m}), 2.58(1 \mathrm{H}, \mathrm{d}, J=12.8 \mathrm{~Hz}), 2.28$ $(1 \mathrm{H}, \mathrm{s}), 2.03-2.00(2 \mathrm{H}, \mathrm{m}), 1.88-1.86(1 \mathrm{H}, \mathrm{m}), 1.78-1.75(1 \mathrm{H}, \mathrm{m})$, 1.71-1.68 (1H, m), 1.62-1.57 (2H, m), 1.52-1.49 (2H, m), 1.42$1.38(1 \mathrm{H}, \mathrm{m}), 1.31(3 \mathrm{H}, \mathrm{s}), 1.27-1.22(5 \mathrm{H}, \mathrm{m}), 1.09(1 \mathrm{H}, \mathrm{d}, J=10.5$ $\mathrm{Hz}), 1.01(1 \mathrm{H}, \mathrm{m}), 1.00(6 \mathrm{H}, \mathrm{s}), 0.91(3 \mathrm{H}, \mathrm{s}), 0.89(3 \mathrm{H}, \mathrm{s}), 0.83(1 \mathrm{H}$, $\mathrm{d}, J=9.1 \mathrm{~Hz}), 0.67(6 \mathrm{H}, \mathrm{s}) ;{ }^{13} \mathrm{C}$ NMR (101 MHz, $\left.d_{6}-\mathrm{DMSO}\right)$ $\delta$ 199.52, 175.91, 170.00, 165.97, 160.66, 138.93, 129.51 (2C), 128.04, 127.84, 119.98, 114.73 (2C), 77.03, 61.58, 55.64, 54.53, $47.92,45.21,43.36,43.26,41.16,39.21,39.06,39.00,37.68$, $37.07,32.56,31.82$ (2C), 30.78, 29.20, 28.63, 28.57, 27.39, 26.46, 26.40, 23.46, 18.65, 17.57, 16.57, 16.44; HRMS (ESI): $\mathrm{m} / \mathrm{z}$ calcd for $\mathrm{C}_{42} \mathrm{H}_{61} \mathrm{~N}_{2} \mathrm{O}_{5}[\mathrm{M}+\mathrm{H}]^{+}$673.4580, found 673.4603.

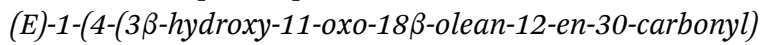
ethanediamine-1-yl)-3-(3,4,5-(trimethoxy)phenyl)-2-propen-1-one (7g). White solid; mp 166.3-167.5 ${ }^{\circ} \mathrm{C}$; yield 58\%; ${ }^{1} \mathrm{H}$ NMR (400 $\mathrm{MHz}, d_{6}$-DMSO) $\delta 8.02(1 \mathrm{H}, \mathrm{s}), 7.64(1 \mathrm{H}, \mathrm{s}), 7.33(1 \mathrm{H}, \mathrm{d}, J=15.7$ $\mathrm{Hz}), 6.85(2 \mathrm{H}, \mathrm{s}), 6.52(1 \mathrm{H}, \mathrm{d}, J=15.7 \mathrm{~Hz}), 5.54(1 \mathrm{H}, \mathrm{s}), 4.28(1 \mathrm{H}$, $\mathrm{d}, J=5.0 \mathrm{~Hz}), 3.79(6 \mathrm{H}, \mathrm{s}), 3.65(3 \mathrm{H}, \mathrm{s}), 3.26-3.11(4 \mathrm{H}, \mathrm{m}), 3.00-$ $2.99(1 \mathrm{H}, \mathrm{m}), 2.57(1 \mathrm{H}, \mathrm{d}, J=12.9 \mathrm{~Hz}), 2.26(1 \mathrm{H}, \mathrm{s}), 2.03-1.99$ $(2 \mathrm{H}, \mathrm{m}), 1.88(1 \mathrm{H}, \mathrm{m}), 1.77-1.74(1 \mathrm{H}, \mathrm{m}), 1.67-1.62(1 \mathrm{H}, \mathrm{m})$, 1.59-1.56 (2H, m), 1.50-1.46 (2H, m), 1.39 (1H, m), $1.30(3 \mathrm{H}, \mathrm{s})$, 1.29-1.21 (6H, m), 1.09 (1H, d, $J=10.0 \mathrm{~Hz}), 1.00(1 \mathrm{H}, \mathrm{m}), 0.99$ $(3 \mathrm{H}, \mathrm{s}), 0.95(3 \mathrm{H}, \mathrm{s}), 0.90(3 \mathrm{H}, \mathrm{s}), 0.88(3 \mathrm{H}, \mathrm{s}), 0.83(1 \mathrm{H}, \mathrm{m}), 0.69$ $(3 \mathrm{H}, \mathrm{s}), 0.65(3 \mathrm{H}, \mathrm{s}) ;{ }^{13} \mathrm{C}$ NMR (101 MHz, $d_{6}$-DMSO) $\delta 199.20$, $175.47,169.62,165.49$, 153.09 (2C), 139.13, 138.64, 130.55, 127.81, 121.33, 104.97 (2C), 76.68, 61.25, 60.13, 55.88 (2C), $54.19,47.53,44.84,43.02,42.91,40.79,38.88,38.81,38.65$, $37.36,36.71,32.20,31.48$ (2C), 30.53, 28.89, 28.34, 28.23, 27.05, 26.13, 26.07, 23.15, 18.24, 17.24, 16.23, 16.09; HRMS (ESI): $m / z$ calcd for $\mathrm{C}_{44} \mathrm{H}_{65} \mathrm{~N}_{2} \mathrm{O}_{7}[\mathrm{M}+\mathrm{H}]^{+}$733.4792, found 733.4821.

(E)-1-(4-(3 $\beta$-hydroxy-11-oxo-18 $\beta$-olean-12-en-30-carbonyl)ethanediamine-1-yl)-2-methyl-3-phenyl-2-propen-1-one(7h). White solid; mp 145.8-147.2 ${ }^{\circ} \mathrm{C}$; yield 51\%; ${ }^{1} \mathrm{H}$ NMR $\left(400 \mathrm{MHz}, d_{6}\right.$ DMSO) $\delta 7.96(1 \mathrm{H}, \mathrm{s}), 7.70(1 \mathrm{H}, \mathrm{s}), 7.41-7.27(5 \mathrm{H}, \mathrm{m}), 7.22(1 \mathrm{H}$, s), $5.51(1 \mathrm{H}, \mathrm{s}), 4.31(1 \mathrm{H}, \mathrm{d}, J=5.0 \mathrm{~Hz}), 3.28-3.20(4 \mathrm{H}, \mathrm{m}), 3.05-$ $2.95(1 \mathrm{H}, \mathrm{m}), 2.58(1 \mathrm{H}, \mathrm{d}, J=12.6 \mathrm{~Hz}), 2.29(1 \mathrm{H}, \mathrm{s}), 2.10-2.01$ (2H, m), 1.99 (3H, s), 1.89-1.88 (1H, m), 1.80-1.77 (1H, m), 1.731.67 (1H, m), 1.62-1.57 (2H, m), 1.52-1.49 (2H, m), 1.47-1.37
(1H, m), 1.30-1.19 (6H, m), $1.32(3 \mathrm{H}, \mathrm{s}), 1.11(2 \mathrm{H}, \mathrm{d}, J=14.3 \mathrm{~Hz})$, $1.01(6 \mathrm{H}, \mathrm{s}), 0.97$ (3H, s), $0.92(1 \mathrm{H}, \mathrm{m}), 0.89(3 \mathrm{H}, \mathrm{s}), 0.68(6 \mathrm{H}, \mathrm{s})$; ${ }^{13} \mathrm{C}$ NMR (101 MHz, $d_{6}$-DMSO) $\delta 199.09,175.74,169.66,168.84$, 136.12, 132.49, 132.30, 129.24 (2C), 128.39 (2C), 127.66, 127.61, $76.65,61.22,54.18,47.60,44.86,42.97,42.92,40.81,38.83,38.59$ (2C), 37.30, 36.72, 32.21, 31.43 (2C), 30.51, 28.81, 28.30, 28.20, $27.03,26.10,26.00,23.10,18.35,17.21,16.22,16.05,14.27$; HRMS (ESI): $m / z$ calcd for $\mathrm{C}_{42} \mathrm{H}_{61} \mathrm{~N}_{2} \mathrm{O}_{4}[\mathrm{M}+\mathrm{H}]^{+} 657.4631$, found 657.4654 .

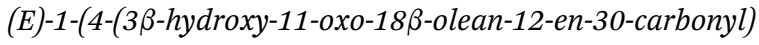
ethanediamine-1-yl)-3-phenylpropyl-1-one (7i). White solid; mp 142.2-143.2 ${ }^{\circ} \mathrm{C}$; yield 67\%; ${ }^{1} \mathrm{H}$ NMR (400 MHz, $d_{6}$-DMSO) $\delta 7.80$ $(1 \mathrm{H}, \mathrm{s}), 7.58(1 \mathrm{H}, \mathrm{s}), 7.24(2 \mathrm{H}, \mathrm{t}, J=7.3 \mathrm{~Hz}), 7.19-7.11(3 \mathrm{H}, \mathrm{m})$, $5.51(1 \mathrm{H}, \mathrm{s}), 4.25(1 \mathrm{H}, \mathrm{s}), 3.17-3.03(4 \mathrm{H}, \mathrm{m}), 3.03-2.96(1 \mathrm{H}, \mathrm{m})$, 2.82-2.74 (2H, m), $2.58(1 \mathrm{H}, \mathrm{d}, J=13.5 \mathrm{~Hz}), 2.38-2.32(2 \mathrm{H}, \mathrm{m})$, $2.31(1 \mathrm{H}, \mathrm{s}), 2.10-2.01(2 \mathrm{H}, \mathrm{m}), 1.87-1.85(1 \mathrm{H}, \mathrm{m}), 1.78-1.73(2 \mathrm{H}$, $\mathrm{m}), 1.63-1.57(2 \mathrm{H}, \mathrm{m}), 1.54-1.46(2 \mathrm{H}, \mathrm{m}), 1.49-1.36(2 \mathrm{H}, \mathrm{m})$, 1.33 (3H, s), 1.30-1.20 (5H, m), $1.13(1 \mathrm{H}, \mathrm{d}, J=10.5 \mathrm{~Hz}), 1.02$ $(3 \mathrm{H}, \mathrm{s}), 1.01(3 \mathrm{H}, \mathrm{s}), 0.99(3 \mathrm{H}, \mathrm{s}), 0.96-0.92(1 \mathrm{H}, \mathrm{m}), 0.90(3 \mathrm{H}, \mathrm{s})$, $0.72(3 \mathrm{H}, \mathrm{s}), 0.70(1 \mathrm{H}, \mathrm{s}), 0.68(3 \mathrm{H}, \mathrm{s}) ;{ }^{13} \mathrm{C}$ NMR $\left(101 \mathrm{MHz}, d_{6}-\right.$ DMSO) $\delta$ 199.09, 175.36, 171.57, 169.66, 141.33, 128.27 (2C), 128.18 (2C), 127.57, 125.87, 76.64, 61.22, 54.17, 47.66, 44.87, 42.93 (2C), 40.81, 38.82, 38.69, 38.58, 37.30, 37.15, 36.71, 32.20, 31.43 (2C), 31.09, 30.48, 28.75, 28.40, 28.18, 27.02, 26.10, 25.99, 23.08, 18.37, 17.20, 16.20, 16.03; HRMS (ESI): $\mathrm{m} / \mathrm{z}$ calcd for $\mathrm{C}_{41} \mathrm{H}_{61} \mathrm{~N}_{2} \mathrm{O}_{4}[\mathrm{M}+\mathrm{H}]^{+}$645.4631, found 645.4659.

\subsection{Pharmacology}

4.2.1 Cell culture and cell viability analysis. In this study, human ovarian cancer cell lines (SKOV3 and OVCAR3) and normal ovarian epithelial cells (IOSE80) were purchased from the Cell Bank of Shanghai Institute of Biochemistry and Cell Biology (Shanghai, China). SKOV3 cells were grown in RPMI1640 medium supplemented with $10 \%$ fetal bovine serum (FBS; Thermo Fisher Scientific, Waltham, MA, USA) and $100 \mathrm{U}$ per $\mathrm{mL}$ penicillin-streptomycin (Sigma-Aldrich; Merck KGaA, Darmstadt, Germany) and incubated at $37{ }^{\circ} \mathrm{C}$ with $5 \% \mathrm{CO}_{2}$. OVCAR3 and IOSE80 cells were grown in Dulbecco's Modified Eagle medium (DMEM, Thermo Fisher Scientific, Waltham, MA, USA). Cell viability was assessed using the MTT assay. The compounds were dissolved in DMSO and the maximum concentration of DMSO did not exceed $0.1 \%(\mathrm{v} / \mathrm{v})$. Cells were incubated on 96 well plates at $1 \times 10^{4}$ cells/well in a final volume of $100 \mu \mathrm{L}$ medium and cultured for $24 \mathrm{~h}$. Then, cells were treated with different concentrations of compounds for $48 \mathrm{~h}$. Then, $50 \mu \mathrm{L}$ of MTT ( $2 \mathrm{mg} \mathrm{mL}{ }^{-1}$ ) was added to each well, and the cells were incubated for $48 \mathrm{~h}$. The supernatant was removed, and $150 \mu \mathrm{L}$ of DMSO was added to each well for $10 \mathrm{~min}$ to dissolve the formazan crystals. After agitated for $10 \mathrm{~min}$, the absorbance was measured at $490 \mathrm{~nm}$ using microplate reader (Molecular Devices, LLC, Sunnyvale, CA, USA). The concentrations to inhibit growth by $50 \%$ were calculated with GraphPad Prism 7.

4.2.2 Apoptosis assay. Cells were plated in 6-well plates and treated with compound for $24 \mathrm{~h}$. Then, cells were harvested, washed, and stained with FITC-conjugated annexin V and 7- 
AAD (BD Biosciences, San Diego, CA, USA) in the dark for $10 \mathrm{~min}$ at room temperature. The stained cells were quantitatively determined the apoptotic cells by flow cytometer (BD FACSCanto, San Jose, CA, USA).

4.2.3 Western blot analysis. Cells were treated with compound for $24 \mathrm{~h}$. Then, cells were harvested and lysed by RIPA buffer. An equivalent amount of protein was separated by $10 \%$ SDS-PAGE and then transferred into PVDF membrane (Millipore, Bedford MA). The membrane was blocked with 5\% defatted dry milk and sequentially incubated with primary antibodies overnight at $4{ }^{\circ} \mathrm{C}$ and secondary antibodies at room temperature for $1 \mathrm{~h}$. Antibodies were obtained from Cell Signalling Technology (Beverly, MA, USA). The membrane was washed with TBST buffer, and the bands were detected using an in an AlPHAImager 2200 (BioTechne, Minneapolis, MN, USA).

4.2.4 Wound healing assay. A total of $1 \times 10^{5}$ cells were seeded in 6-well culture plates and were allowed to grow to $80 \%$ confluence. An artificial wound was created by a sterile $10 \mu$ Ltip, and the detached cells were washed off gently. Then, cells were incubated in the presence of different concentrations compound. Finally, the gap created was measured after $24 \mathrm{~h}$ using an inverted microscope (CKX71, Olympus Corporation, Tokyo, Japan). The wound width was analysed by ImageJ software.

4.2.5 Cell migration assay. Cell migration was studied with transwell chambers in 24-well plates (Corning Inc., Tewksbury, MA, USA). $5 \times 10^{4}$ cells in suspension serum-free medium containing compound were seeded into the upper chambers. A total volume of $0.6 \mathrm{~mL}$ medium contained $10 \%$ FBS was added to the lower chamber. After $24 \mathrm{~h}$, cells located in the upper membrane were removed lightly. The bottom of the membrane was stained with $0.5 \%$ crystal violet (Sigma-Aldrich; Merck KgaA, Darmstadt, Germany) for 15 min after fixed with $4 \%$ paraformaldehyde for $15 \mathrm{~min}$. The crystal violet positive cells were counted.

4.2.6 Colony formation assay. 300 cells were diluted in $2 \mathrm{~mL}$ culture medium and plated in 6-well plates for $24 \mathrm{~h}$. Then, cells were treated with compound at indicated concentrations. The cells were then cultured for 10 days. Finally, the cells were fixed with $4 \%$ paraformaldehyde for $30 \mathrm{~min}$ and stained with $0.5 \%$ crystal violet for $15 \mathrm{~min}$. Plates were photographed, and colonies were counted by ImageJ software. Images are shown as representatives of three independent experiments.

4.2.7 Sphere formation assay. Cells were seeded at a density of $5 \times 10^{3}$ cells per well in 6-well ultralow attachment plates (Corning Inc., Corning, NY, USA) at $37{ }^{\circ} \mathrm{C}$ with $5 \% \mathrm{CO}_{2}$. Cells were incubated with DMEF/F12 (1:1) with B-27 (Thermo Fisher Scientific, Grand Island, NY, USA), $10 \mathrm{ng} \mathrm{mL}^{-1}$ fibroblast growth factor-basic (bFGF, R\&D, Minneapolis, MN, USA), and 10 ng $\mathrm{mL}^{-1}$ epidermal growth factor (EGF, Gibco, Carlsbad, CA, USA). After 10 days, tumourspheres were harvested, and then equal cells were plated to form secondary generation. The compound was added at indicated concentrations after plating for $24 \mathrm{~h}$. Cells were cultured for a subsequent 10 days. The culture medium with the compound was replaced three times during incubation. The cells were visualized, and the number of spheres $(>50 \mu \mathrm{m})$ was counted using an inverted microscope (CKX71, Olympus Corporation, Tokyo, Japan)

4.2.8 Flow cytometry analysis. Cells were treated with compound for $24 \mathrm{~h}$ and then harvested. Cells were washed with cold phosphate-buffered saline (PBS) and counted. The cell of each group was adjusted to $1 \times 10^{6}$ cells per $\mathrm{mL}$. Approximately $100 \mu \mathrm{L}$ of the cell suspension was incubated with specific fluorescein isothiocyanate (FITC)-conjugated anti-human CD44 or CD133 (BD Biosciences, San Diego, CA, USA) in the dark for $0.5 \mathrm{~h}$. IgGof the same isotype and same species was used as an isotype control for each antibody. Cells were analysed using a flow cytometer (BD FACS Canto, San Jose, CA, USA).

4.2.9 ALDEFLUOR ${ }^{\mathrm{TM}}$ kit ALDH analysis. The population of $\mathrm{ALDH}^{+}$was measured by an ALDEFLUOR ${ }^{\mathrm{TM}}$ assay kit according to the manufacturer's instructions (Stemcell Technologies, Vancouver, BC, Canada). Cells were treated with compound at indicated concentrations for $24 \mathrm{~h}$. Then, cells were harvested and suspended using ALDEFLUOR ${ }^{\mathrm{TM}}$ assay buffer to prepare samples with a concentration of $1 \times 10^{6}$ cells per mL. $1 \mathrm{~mL}$ sample and $5 \mu \mathrm{L}$ activated ALDEFLUOR reagent was added into a tube and mixed rapidly. Next, $0.5 \mathrm{~mL}$ mixture was transferred to another tube with an added $5 \mu \mathrm{L}$ ALDH inhibitor diethylaminbenzaldehyde (DEAB) as a negative control. All tubes were mixed quickly and incubated for 40 minutes at $37^{\circ} \mathrm{C}$. All samples were centrifuged and resuspended in $0.4 \mathrm{~mL}$ of ALDEFLUOR $^{\mathrm{TM}}$ assay buffer. Finally, all samples were subjected to FACS analysis.

4.2.10 Statistical analysis. Data were presented as means \pm standard deviations (SD), and statistical analysis was conducted using SPSS 19.0 software. The significance of the difference between compared groups was determined with the student's $t$ test. All data are representative of the experiment carried out in triplicate. The mean was considered significantly different if $P<$ 0.05 .

\section{Conflicts of interest}

The authors declare no conflict of interest.

\section{Acknowledgements}

This work was supported by the Natural Science Foundation of Shandong Province (ZR2016HB05, ZR2016HB45 and ZR2019PC030), the open project of Shandong Collaborative Innovation Centre for Antibody Drugs (CIC-AD1827), the Postdoctoral Science Foundation of China (2018M632607), and the National Natural Science Foundation of China (81600087).

\section{Notes and references}

1 B. M. Reid, J. B. Permuth and T. A. Sellers, Cancer Biol. Med., 2017, 14, 9-32.

2 L. A. Torre, B. Trabert, C. E. DeSantis, K. D. Miller, G. Samimi, C. D. Runowicz, M. M. Gaudet, A. Jemal and R. L. Siegel, CA A Cancer J. Clin., 2018, 68, 284-296. 
3 Z. Pieterse, M. A. Amaya-Padilla, T. Singomat, M. Binju, B. D. Madjid, Y. Yu and P. Kaur, Int. J. Biochem. Cell Biol., 2019, 106, 117-126.

4 J. E. Visvader and G. J. Lindeman, Nat. Rev. Cancer, 2008, 8, 755-768.

5 M. E. Toledo-Guzman, G. D. Bigoni-Ordonez, M. Ibanez Hernandez and E. Ortiz-Sanchez, World J. Stem Cells, 2018, 10, 183-195.

6 B. C. Prager, Q. Xie, S. Bao and J. N. Rich, Cell Stem Cell, 2019, 24, 41-53.

7 M. K. Siu, E. S. Wong, D. S. Kong, H. Y. Chan, L. Jiang, O. G. Wong, E. W. Lam, K. K. Chan, H. Y. Ngan, X. F. Le and A. N. Cheung, Oncogene, 2013, 32, 3500-3509.

8 A. Mihanfar, J. Aghazadeh Attari, I. Mohebbi, M. Majidinia, M. Kaviani, M. Yousefi and B. Yousefi, J. Cell. Physiol., 2019, 234, 3238-3253.

9 W. F. Taylor and E. Jabbarzadeh, Am. J. Cancer, 2017, 7, 15881605.

10 F. Pistollato, R. Calderon Iglesias, R. Ruiz, S. Aparicio, J. Crespo, L. Dzul Lopez, F. Giampieri and M. Battino, Cancer Lett., 2017, 411, 191-200.

11 X. Li, H. Wang, J. Ding, S. Nie, L. Wang, L. Zhang and S. Ren, Eur. J. Pharmacol., 2019, 842, 146-156.

12 D. J. Newman and G. M. Cragg, J. Nat. Prod., 2007, 70, 461477.

13 G. M. Cragg and D. J. Newman, Biochim. Biophys. Acta, 2013, 1830, 3670-3695.
14 H. Hussain, I. R. Green, U. Shamraiz, M. Saleem, A. Badshah, G. Abbas, N. U. Rehman and M. Irshad, Expert Opin. Ther. Pat., 2018, 28, 383-398.

15 X. F. Wang, Q. M. Zhou, Y. Y. Lu, H. Zhang, S. Huang and S. B. Su, Expert Opin. Ther. Targets, 2015, 19, 577-587.

16 F. Zhou, G. R. Wu, D. S. Cai, B. Xu, M. M. Yan, T. Ma, W. B. Guo, W. X. Zhang, X. M. Huang, X. H. Jia, Y. Q. Yang, F. Gao, P. L. Wang and H. M. Lei, Eur. J. Med. Chem., 2019, 178, 623-635.

17 L. Jin, L. Dai, M. Ji and H. Wang, Bioorg. Chem., 2019, 85, 179-190.

18 R. Wang, W. Yang, Y. Fan, W. Dehaen, Y. Li, H. Li, W. Wang, Q. Zheng and Q. Huai, Bioorg. Chem., 2019, 88, 102951.

19 B. Xu, G. R. Wu, X. Y. Zhang, M. M. Yan, R. Zhao, N. N. Xue, K. Fang, H. Wang, M. Chen, W. B. Guo, P. L. Wang and H. M. Lei, Molecules, 2017, 22, 924.

20 Y. Li, L. Feng, Z. F. Song, H. B. Li and Q. Y. Huai, Molecules, 2016, 21, 199.

21 P. Su, Y. Shi, J. Wang, X. Shen and J. Zhang, Anti Cancer Agents Med. Chem., 2015, 15, 980-987.

22 Z. Zhao, H. Song, J. Xie, T. Liu, X. Zhao, X. Chen, X. He, S. Wu, Y. Zhang and X. Zheng, Eur. J. Med. Chem., 2019, 173, 213-227.

23 D. Kim, B. H. Choi, I. G. Ryoo and M. K. Kwak, Cell Death Dis., 2018, 9, 896. 